University of Louisville

ThinkIR: The University of Louisville's Institutional Repository

Electronic Theses and Dissertations

7-2017

\title{
Investigation of lattice structures and analysis of strut geometry.
}

Zachary D Denzik

University of Louisville

Follow this and additional works at: https://ir.library.louisville.edu/etd

Part of the Other Mechanical Engineering Commons

\section{Recommended Citation}

Denzik, Zachary D, "Investigation of lattice structures and analysis of strut geometry." (2017). Electronic Theses and Dissertations. Paper 2814.

https://doi.org/10.18297/etd/2814

This Master's Thesis is brought to you for free and open access by ThinkIR: The University of Louisville's Institutional Repository. It has been accepted for inclusion in Electronic Theses and Dissertations by an authorized administrator of ThinkIR: The University of Louisville's Institutional Repository. This title appears here courtesy of the author, who has retained all other copyrights. For more information, please contact thinkir@louisville.edu. 
INVESTIGATION OF LATTICE STRUCTURES

AND

ANALYSIS OF STRUT GEOMETRY

By

Zachary David Denzik

B.S., University of Louisville, 2016

A Thesis

submitted to the Faculty of the

University of Louisville

J.B. Speed School of Engineering

as Partial Fulfillment of the Requirements

for the Professional Degree

MASTER OF ENGINEERING

Department of Mechanical Engineering

July 2017 


\section{TABLE OF CONTENTS}

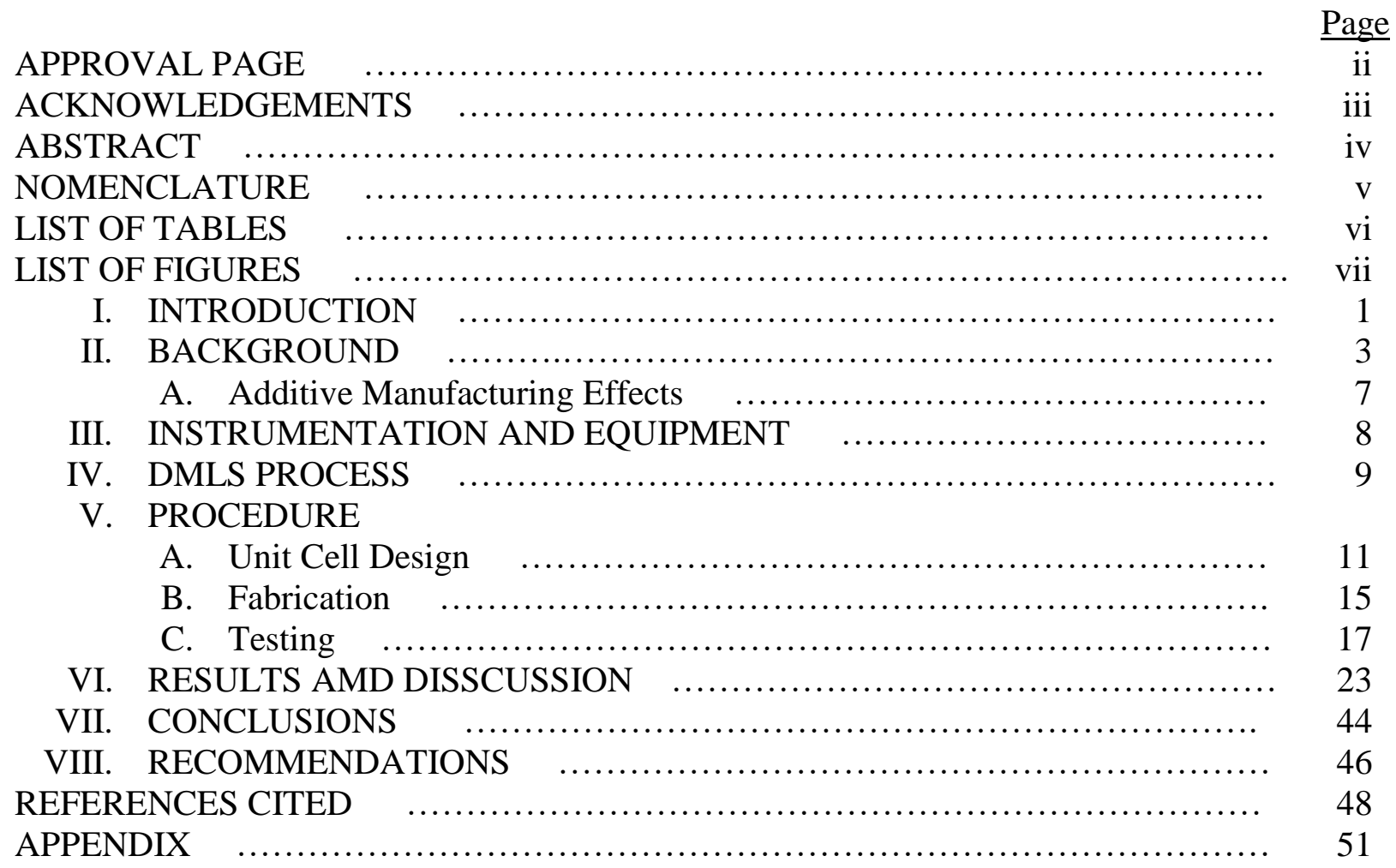




\section{Investigation of lattice structures and \\ Analysis of strut geometry}

Submitted by:

Zachary David Denzik

A Thesis Approved on

(Date)

by the Following Reading and Examination Committee:

Dr. Thomas Berfield, Thesis Director

Dr. Thomas Starr

Dr. Li Yang

\section{Tim Gornet}




\title{
ACKNOWLEDGEMENTS
}

\author{
Dr. Tom Berfield \\ Dr. Tom Starr \\ Dr. Li Yang \\ Tim Gornet \\ Niknam Momenzadeh \\ Joe Vicars and Gary Graf \\ Rapid Prototyping Center \\ American Axle and Manufacturing
}

I would like to acknowledge Dr. Tom Berfield, Dr. Tom Starr, Dr. Li Yang, Mr. Tim Gornet, and Mr. Niknam Momenzadeh for their assistance in the analysis of the lattice structures. Also, the help of Mr. Joe Vicars and Mr. Gary Graf for all their guidance and assistance with modeling, fabrication, and testing of all lattice specimens. The assistance of the Rapid Prototyping Center at the J.B. Speed School of Engineering at the University of Louisville was instrumental in the fabrication, cleaning and testing of all samples. Finally, American Axle and Manufacturing automotive company for funding of the project and research. 


\begin{abstract}
This study involves the evaluation of lattice specimens fabricated using additive manufacturing as well as investigation of the influence of unit cell connection geometry. Lattice topologies of face-centered cells and body-centered cells were modeled, investigated using finite element analysis (FEA) for each specimen, manufactured using direct metal laser sintering (DMLS) with maraging steel powder, and mechanically tested. The strut diameter of each topology was altered to yield four different mass reductions from a solid cube of maraging steel, ranging from $55 \%-90 \%$ mass reduction. Three iterations of $1000 \mathrm{~mm}^{3}$ lattice specimens were investigated. The first iteration consisted $0.5 \mathrm{~mm}$ plates on the top and bottom of the lattice tested only in compression. While the mechanical testing results yielded increasing stiffness to increasing strut diameter, the results were poor in comparison to FEA results, ranging from only $7 \%$ to $20 \%$ of FEA stiffness results. A second iteration was modeled to enable the testing of specimens in either compression or tension as well as the use of an extensometer during testing. The results for the second iteration of specimens improved from first iteration and showed that as strut diameter is increased, the stiffness and effective modulus of each unit cell increases. All stiffness results from the second iteration specimens were greater than that of FEA results, ranging from $150 \%$ to $215 \%$ of FEA stiffness in tension and $125 \%$ to $400 \%$ of FEA stiffness in compression. The final iteration of specimens would add fillets at the strut-additional mass connections, testing connection stiffness and effective modulus of increasing fillet size when compared to no fillet connections. With the addition of fillets, mass is being added back to the unit cell. The most mass added to a unit cell was only a $4 \%$ increase in mass. But, with added mass came an increase in both stiffness and effective modulus in most parts. A select few of these fillet and non-fillet specimens were also tested to failure but without the use of an extensometer. While the stiffness results yielded poor comparisons to previous tests, these tests characterized the stress concentration behavior between non-fillet and fillet specimens. While non-filleted specimens tended to fail at strut-to-additional mass connections, the filleted specimens tended to fracture inside the lattice unit cell.
\end{abstract}




\section{NOMENCLATURE}

Face-centered unit cell topology $=$ FCC

Body-centered unit cell topology $=\mathrm{BCC}$

Finite element analysis = FEA

Direct metal laser sintering $=$ DMLS

EOS Direct metal laser sintering M270 machine $=$ M270

Instron 5569A tensile and compression tester $=$ Instron 


\section{LIST OF TABLES}

Table 1. Properties used in FEA to represent EOS MS1 $\quad \ldots \ldots \ldots \ldots \ldots \ldots \ldots \ldots \ldots \ldots \ldots \ldots \ldots \ldots \ldots$

Table 2. Listed strut diameters for each topology with associated weight reduction

Table 3. Calculated stiffness' from FEA

load and displacement results

Table 4. Percent stiffness of tested specimens to FEA models

Table 6. Weight comparison between modeled and printed second iteration specimens

Table 7. Measured verses modeled FEA compression stiffness comparison

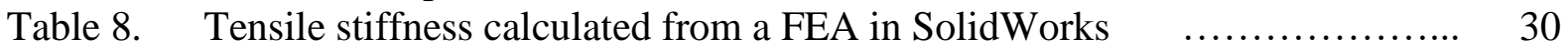

Table 9. Compressive and tensile stiffness in each tested specimen $\quad \ldots \ldots \ldots \ldots \ldots \ldots . . . . . .31$

Table 10. Tension and compression testing stiffness' compared to FEA results

Table 11. Weight comparisons for all FCC fillet specimens $\quad \ldots \ldots \ldots \ldots \ldots \ldots \ldots \ldots . \ldots . \ldots . \ldots . \ldots$

Table 12. Weight comparisons for all BCC fillet specimens $\quad \ldots \ldots \ldots \ldots \ldots \ldots \ldots \ldots . . . \ldots . \ldots$

Table 13. Comparison of modeled to measured filleted FCC specimens

Table 14. Comparison of modeled to measured filleted BCC specimens

Table 15. FCC filleted specimen compressive and tensile stiffness'

Table 16. BCC filleted specimen compressive and tensile stiffness' $\quad$................ 37

Table 17. Tensile failure results for FCC specimens.

Table 18. Tensile failure results for BCC specimens.

Table 19. Transition stress and maximum stress during failure testing of FCC specimen.

Table 20. Transition stress and maximum stress during failure testing of BCC specimen. 


\section{LIST OF FIGURES}

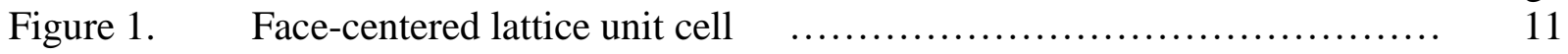

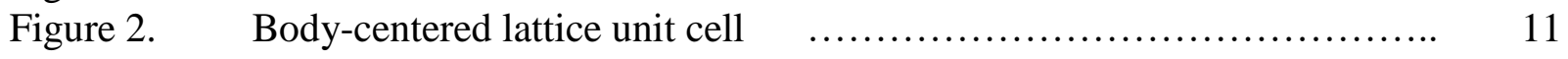

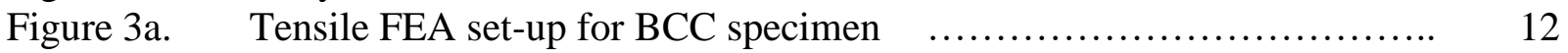

Figure 3b. Compression FEA set-up for FCC specimen $\quad \ldots \ldots \ldots \ldots \ldots \ldots \ldots \ldots \ldots . . \ldots \ldots$

Figure 4. Displacement in both tension and compression simulation $\ldots \ldots \ldots \ldots . . .14$

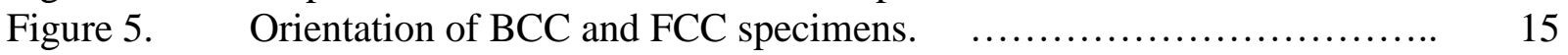

Figure 6. Supports generated for BCC and FCC specimens $\quad \ldots \ldots \ldots \ldots \ldots \ldots \ldots . . . \ldots$

Figure 7a. Post-machining of printed first iteration BCC specimens $\quad \ldots \ldots \ldots \ldots \ldots . .17$

Figure 7b. Post-machining of printed first iteration FCC specimens $\quad \ldots \ldots \ldots \ldots \ldots . . . . .17$

Figure 8. Machined surface of first iteration specimens $\quad \ldots \ldots \ldots \ldots \ldots \ldots \ldots \ldots \ldots . \ldots \ldots$

Figure 9a. Second iteration of BCC specimens with $\quad \ldots \ldots \ldots \ldots \ldots \ldots \ldots \ldots \ldots . \ldots . \ldots . \ldots . \ldots 18$

Figure 9b. Second iteration of FCC specimens with $\quad \ldots \ldots \ldots \ldots \ldots \ldots \ldots \ldots \ldots \ldots \ldots \ldots \ldots$ additional masses and support generation

Figure 10a. Printed second iteration BCC specimen $\quad \ldots \ldots \ldots \ldots \ldots \ldots \ldots \ldots \ldots \ldots . \ldots \ldots$

Figure 10b. Printed second iteration FCC specimen $\quad$........................... 19

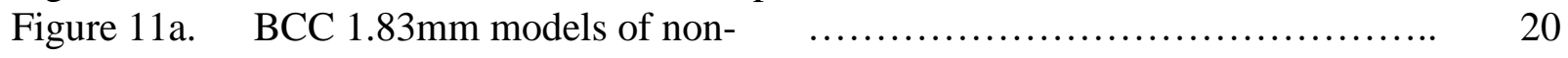

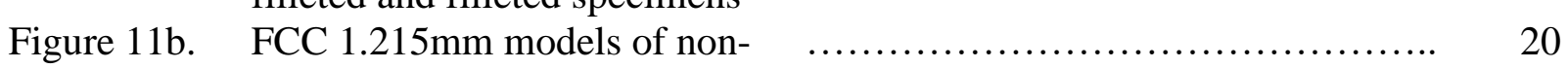

filleted and filleted specimens

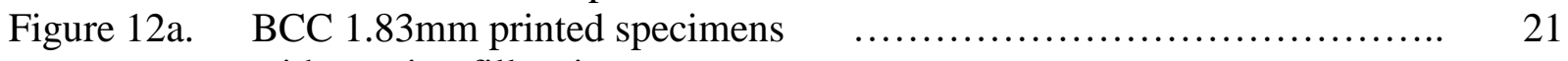
with varying fillet sizes post grinding

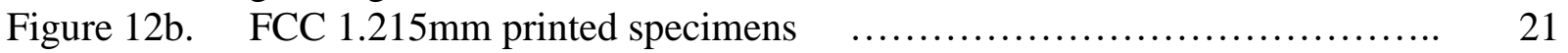
with varying fillet sizes post grinding

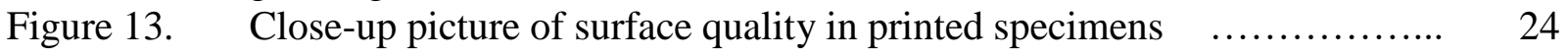

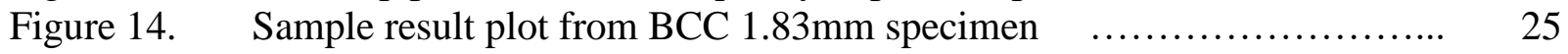

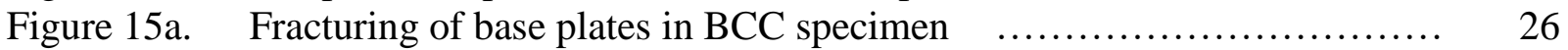

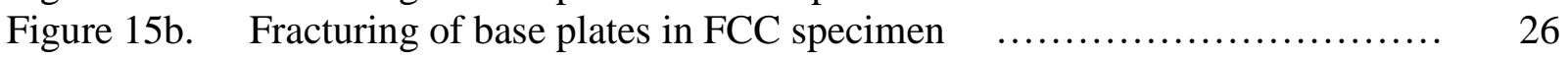

Figure 16. Effective tensile modulus per unit cell $\quad \ldots \ldots \ldots \ldots \ldots \ldots \ldots \ldots \ldots \ldots . . . \ldots \ldots$

density compared to solid maraging steel.

Figure 17. Effective tensile modulus per unit cell $\quad \ldots \ldots \ldots \ldots \ldots \ldots \ldots \ldots \ldots \ldots . \ldots . \ldots . \ldots$ density of filleted specimens compared to solid maraging steel.

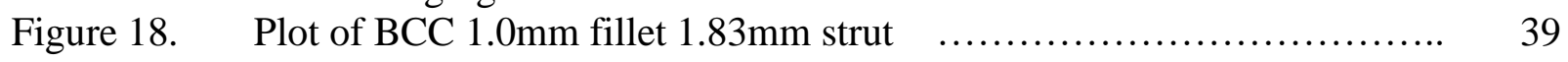
diameter specimen to failure in tension.

Figure 19. Failure of non-fillet and fillet specimens. Left to right: $\quad \ldots \ldots \ldots \ldots \ldots \ldots .42$ No fillet, $0.5 \mathrm{~mm}$ fillet, $1.0 \mathrm{~mm}$ fillet, $1.5 \mathrm{~mm}$ fillet 


\section{INTRODUCTION}

Generally, in industries such as aerospace and automotive, the lighter a machine is the more efficient it will be [1] [2]. One way of reducing the weight is simply removing the internal mass of the structural components inside the machines. By taking mass away, there is physically less material than before, making the whole vehicle or aircraft lighter. A term related to this tactic used in industry is called "mass-decompounding", which means by using lighter materials (even simply cutting material from a part) one can cut overall costs and improve system efficiencies [3]._However, by removing material, the mechanical properties of manufactured components are influenced due to reduced internal support, which makes them less rigid. To maintain mechanical properties, internal lattice structures can be added where solid mass was removed. These structures serve as reinforcement to the surface walls of the part where a void would not, and have a greater stiffness-to-weight ratio when compared to a solid internal material.

Cellular lattice structures contain the intersections of three parallel planes, producing a three-dimensional figure with six faces. Each face is set in one of the three sets of parallel planes, thus making a figure known as a parallelepiped [4]. Lattice structures have connections between these planes via struts. These struts can be constructed using a wide variety of geometries, sizes and orientations. Lattice structures are typically so complex that the only way to fabricate them is to use additive manufacturing. Traditional subtractive manufacturing techniques are not suitable to produce intricate internal lattice structures, especially in metals, due to their complexity and small feature size. The struts and pore size within the lattice are typically smaller than most milling tools. 
In this study, two types of lattices will be looked at: Face-Centered (FCC) and BodyCentered (BCC), (both only focusing on a single unit cell). For both types, the strut diameter will be adjusted within the unit cell to yield different weight and mass reduction from a solid $1000 \mathrm{~mm}^{3}$ cube. This study differs from previous lattice studies performed in that the strut geometry will be studied: the addition of fillets to the connection of strut to solid mass. Also, the lattice specimens will be fabricated using additive manufacturing techniques using a maraging steel powder.

With the removal of internal mass from a structural component, it can become less rigid. But, with lattice structures, the strength-to-weight ratio is much greater than that of solid materials, which is more desirable. This study will look at the stiffness-to-weight ratio and effective modulus-to-weight ratio in both the FCC and BCC specimens with varying strut diameters. Also, potentially determine whith unit cell configuration more closely maintains stiffness when compared to a solid cube of maraging steel. To determine each specimen's stiffness and effective modulus, an Instron tensile tester will be used. Specimens will be tested in both tension, using wedge grips to grab the added mass sections of each lattice, and compression, using a set of compression fixtures and hardened steel plates. These results will be verified and compared to an EOS material sheet for the maraging steel powder used as well as compared to studies performed using lattice structures and maraging steel. 


\section{BACKGROUND}

A number of topics arise with this study have been the subject of previous investigation. Specifically, the topics of cellular lattice designs, lightweight structures, maraging steel or EOS MS1, fillets and stress concentration are highly relevant to the current work. Also researched were additive and subtractive technologies and the comparison of parts made for each process.

The effective mechanical properties of a lattice-based component are intricately linked to the design of the individual unit cell. Particular designs can be engineered to emphasize energy absorbing characteristics. When designing these lattice structures though, the manufacturability and printability can be a concern. Yan and Hao studied this as well as the performance of printed AlSi10Mg "diamond" cellular lattice structures [5]. They concluded that parts can be manufactured through Direct Metal Laser Sintering (DMLS) to have a well-defined geometry, yet partially sintered particles were bonded to the surface. This yielded a higher strut diameter than modeled, ranging from approximately $10 \%$ to $20 \%$ increase. The study also showed that as strut geometry increased, thus making pore size within the lattice smaller, the compressive strength increased. This is expected as more mass is being added to the unit cell which creates a greater resistance to a compressive load, increasing the overall effective strength of the unit cell. Other studies such as Young [6] and Contuzzi [7] show similar results. Young used a gyroid lattice geometry, which is an infinitely connected triply periodic minimal surface that exhibits circular struts and a spherical core, and concluded that by increasing the volume size of the lattice features within the unit cell (meaning pore size is decreasing) the compressive strength as well as the microhardness increases. A microhardness test was performed on all specimens to determine an accurate density for each specimen. The microhardness test was also performed on individual lattice struts and for all specimens it was determined that all individual struts were 
fully dense post-building. Contuzzi studied a pillar textile lattice geometry and concluded that the more vertical reinforcements in the unit cell, a greater compressive loading capacity was achieved. The example used was that by adding eight vertical reinforcements, the loading capacity doubled.

Alsalla studied the effects of build orientation of the lattice structures [8]. The study was performed using stainless steel powder and a gyroid lattice. It was concluded that build orientation of the lattice influence testing results. Periodic lattices printed in the vertical direction had approximately $60 \%$ increase in strength when compared to the horizontally printed lattices. Elongation under tensile loading was also greater, showing $40 \%$ increase in the vertical specimens compared to horizontal specimens. This study also concluded that in both vertical and horizontal orientations of lattices, the part densities were the same in both specimens. As stated, lattice structures have already been introduced into both automotive and aviation industries. For example, Boeing has fabricated an ultralight metallic microlattice that can sit on a dandelion because it is so light [9]. They claim the lattice is $99 \%$ air and is produced using a method involving the use of a liquid photo-polymer which solidifies when hit by ultraviolet radiation. Only the cross-section of the liquid exposed to the ultraviolet rays become solid, creating a lattice-work scaffold, which is then coated with nickel-phosphorous. Once the photopolymer is etched away, all that is left is a 3D, hollow lattice of metal. This can show that lattice structures can create ultra-lightweight structures, but can maintain mechanical properties or have certain responses associated with the material used. Other studies performed about lattice involve proposing a theoretical force-based method to calculate the mechanical properties of the lattice structure fabricated via selective laser melting [10], cellular samples based on four architectures: solid, hollow, lattice structure and rotated lattice structure [11], and evaluation of the 
manufacturability and performance of SLM produced periodic cellular lattice structures, density and compression properties of the cellular lattice structures [12].

Hendrickson studied high production tooling material using DMLS [13]. The study looked at MS1 powder as well as stainless steel and aluminum alloy powders. After performing uniaxial tensile tests on printed samples, results of maraging steel aligned with published values of EOS MS1 [14]. They also looked at the strength and toughness of printed fully dense MS1 via Charpy impact testing, Vickers hardness tests, hydro-burst and leak rate. Hendrickson concluded that printed maraging steel strength is lower than wrought material, but the toughness of the material was more than twice that of wrought material. A study performed by Kempen looked at the microstructure and mechanical properties of DMLS produced maraging steel parts as well as heat treatment of printed parts [15]. The study concluded that due to the layering process performed in DMLS, this causes high density parts to be fabricated as well as introduce natural age hardening in the parts. With the addition of heat treatment, ultimate tensile strength almost doubles but the elongation decreases nearly by a factor of ten. Other articles about maraging steel involve an experimental investigation of Charpy impact testing with maraging steel SLM parts and a comparison with titanium alloy powder, Ti-6Al-4V and stainless steel 316L powder [16], the investigation of the affect the scan spacing, layer thickness, and various heat treatments on microstructure and mechanical properties of maraging steel 300 after selective laser [17], and evaluation of the density, surface quality, mechanical properties, and microstructure of differing scanning strategies of maraging steel [18]. More details about EOS MS1 powder: material properties, printing details, applications of the material, and design guidelines can be found here [19]. 
The influence of stress concentration was also reviewed since this study was to test the effects of filleted connections verses sharp connections within the lattice unit cell. A group of individuals at California State Polytechnic University looked at the effects of stress in different geometry discontinuities within a rectangular specimen [20]. They visualized the effects of having a discontinuity such as a sharp corner, hole, or quick change in cross section. They showed that these locations have an increase in stress when compared to a uniform crosssectioned part. A study performed by Joshi and Karma showed the amount of deflection that occurs when changing the fillet radius in a spur gear using finite element analysis, FEA [21] They concluded that by increasing fillet size to a certain point in which the fillet geometry made a perfect circle inside the gear teeth, the deflection in the teeth decreases. Once that point is reached and the fillet radii increased further, therefore not making a perfect circle in the teeth section of the spur gear, the amount of deflection inside the gear starts to increase. Both of these articles indicate that with the addition of fillets to the sharp strut connections within a lattice cell should effectively decrease the stress concentration at these locations. And, depending on the expected failure mode, the effective strength of the lattice structures could be improved. This also agrees with the previously mentioned articles about lattice cells. As you increase cell volume, the pore size decreases and the strength of the cell will increase. Further studies about fillets, such as the investigation of varying fillet radius within a spur gear and amount of deflection that occurs using FEA [22], an experimental study of different fillet configurations at the corner of airfoils and how these configurations affect boundary layer growth [23], and the resulting stresses that occur within gear teeth with varying fillet sizing [24], have been performed. 


\section{A. Additive Manufacturing Effects}

Differentiating between additive and subtractive manufacturing was also researched. Wright points out the pros and cons of each manufacturing process and how each is suited to particular parts [25]. Wright points out that any part in metals that is designed for subtractive manufacturing should be made in this process and would be a waste of time to build these types of parts using additive manufacturing. This is because of the time to fabricate using additive manufacturing is much longer due to the volume of computer numerical control (CNC) made parts typically are much larger in volume. If built using additive processing techniques, a part could take ten times longer or more as opposed to fabricating a part modeled for CNC milling or any other subtractive manufacturing technique. Also, CNC parts typically have large crosssections and are solid parts, which cause problems inside the build chamber of an additive manufacturing machine. These problems will be discussed later. However, Wright does state that if a part has features that are impossible to machine, such as a sharp internal corner or any internal hollow geometry, additive manufacturing is the only viable option. As pointed out before, manufacturing small structures like lattices should only be attempted to fabricate in an additive manufacturing machine. Other comparisons between additive and subtractive manufacturing can be found here [26] [27]. 


\section{INSTRUMENTATION AND EQUIPMENT}

The structures used in this study were modeled using Dassault Systems SolidWorks. SolidWorks is a solid modeling computer-aided design and computer-aided engineering software. Through SolidWorks, all geometries were modeled as well as simulated. A finite element analysis, FEA, was performed for each geometry to identify each specimen's stiffness. To fabricate each specimen for physical testing, an EOS M270 direct metal laser sintering machine was used. To print in the EOS M270, each part model must be saved as a stereolithography, stl, file from SolidWorks first. From there, each specimen's .stl file will be opened in Materialise Magics, another computer-aided engineering software. This software is utilized for generating supports for each part printed in metal. This software will analyze the part for areas needing support as well as allows the user to manually create supports. Lastly, from Magics, the program SliView will be used to slice each part and supports into the correct number of cross-sectioned layers in which the EOS M270 will use to scan the part. The layer thickness for this study is 40 microns. Once each part is sliced, all parts are loaded into the EOS M270 software, positioned, and saved as a single build file. Finally, when the build is completed, all parts are cut from the build plate using a vertical bandsaw. Any support attached to the part is removed from the part. All parts are cleared of excess powder trapped inside the lattice structure that was not sintered. After all post-build cleaning processes, each part was tested using an Intron 5569A tension and compression tester. Both capabilities were used in this study. 


\section{DMLS PROCESS}

Direct Metal Laser Sintering, DMLS, is an additive manufacturing process in which metal particles are sintered together using a high wattage fiber laser. The laser outlines and scans each cross-section of the part being printed. Once a layer is scanned, the build platform will descend one layer thickness and an arm will recoat a new layer of powder onto the build platform so that the next layer can be scanned. This continues layer by layer until the part has been scanned entirely. Each part is also scanned directly to a build plate and cut off after the build is completed. Since DMLS is simply welding particles together, you need a starting material to weld to, hence the need for a build plate. Parts can either be sintered directly to a build plate or, through the use of supports, can be offset from the build plate so that when cutting parts off of the build plate there is not any damage to the parts by cutting into them. Supports are a separate file uploaded to the EOS M270 and has different scanning parameters than the part being printed. Support is used on any overhangs in the part as well as areas such as undercuts and hollow features to ensure parts build correctly [28]. If any angle in relation to the build plate is less than $45^{\circ}$, support will be generated in this area. This is to help with print quality by keeping warping within the part as minimal as possible. Warping within a part comes from the heating of particles with a laser at high laser scan speeds. This causes high cooling speeds to occur once the laser has finished scanning. With this action occurring over and over, layer by layer, this causes residual stress to internalize in the part being printed [29]. This stress can cause the part to warp and curl as the build is running. If these stresses become too great and the part deforms enough, collision with the warped part and the recoating arm can occur. A build cannot be restarted with a warped part. Support also keeps everything connected. In DMLS, if the laser scans powder that is not connected to anything or is loosely connected to the part, there is a high 
chance of failure of the build or collision of the loosely scanned particles with the recoating blade, which causes the entire building process to be stopped and the build to be discarded. For more information about EOS DMLS processes and materials [30]. For more information about the DMLS process in general [31] [32] [33]. 


\section{PROCEDURE}

\section{A. Unit Cell Design}

For this study, two different topologies were used: face-centered cells (FCC) and bodycentered cells (BCC). Each specimen lattice was contained within a $10 \mathrm{~mm} \times 10 \mathrm{~mm} \times 10 \mathrm{~mm}$ cube. The FCC specimens consist of struts only crossing along the faces of the unit cell leaving the internal volume of the cube vacant. The BCC specimens consist of struts crossing in the center of the unit cell leaving the walls of the cube vacant. All lattice specimen was modeled in Dassault Systems SolidWorks. Each topology includes struts at the corners of each cube. Figure 1 and Figure 2 show each modeled topology from SolidWorks.

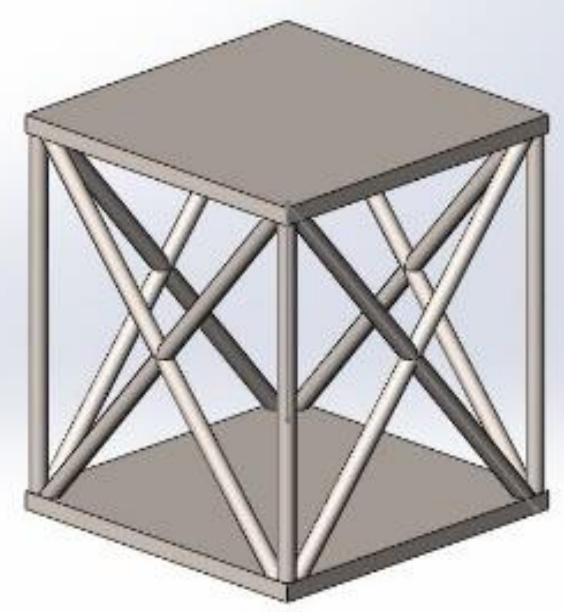

Figure 1. Face-centered lattice unit cell.

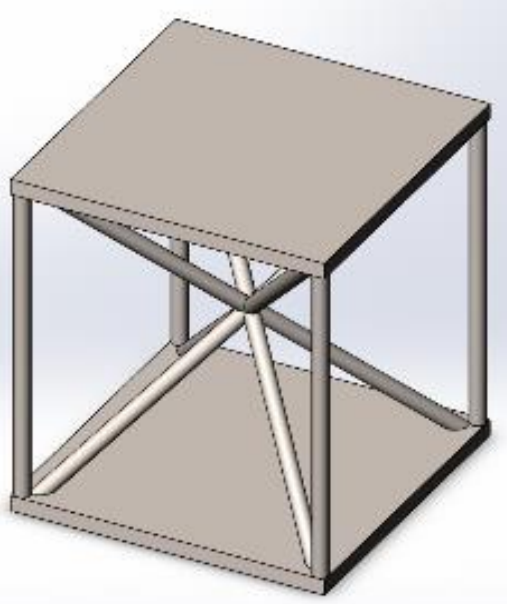

Figure 2. Body-centered lattice cell.

Each topology's strut diameters were adjusted to yield certain weight reductions from a solid $1000 \mathrm{~mm}^{3}$ cube, ranging from approximately $55 \%$ reduction to $90 \%$ reduction. Two types of specimen strut geometry were tested - some with all strut diameters uniform per specimen and others with fillets added to the strut-additional mass connection. All calculations of mass and weight reduction were performed in SolidWorks using alloy steel as material type. These 
calculations were determined using SolidWorks' mass properties tool once a strut diameter was specified and modeled. Each specimen was compared to a solid $1000 \mathrm{~mm}^{3}$ cube of alloy steel.

Once all specimens were modeled and weight reductions were calculated, a finite element analysis, FEA, was performed for each to calculate the stiffness in each specimen. An assembly was created in SolidWorks consisting of the lattice structure, edited to as closely resemble EOS maraging steel, and two thick plates, edited to be enormously stiff when compared to EOS maraging steel. A single plate was mated on either side of the lattice. The plate on the bottom of the lattice was fixed. The top plate had a 4000N force applied in both tension and compression. Figure 3 shows the FEA set-up of both the tension and compression simulations.

(a)

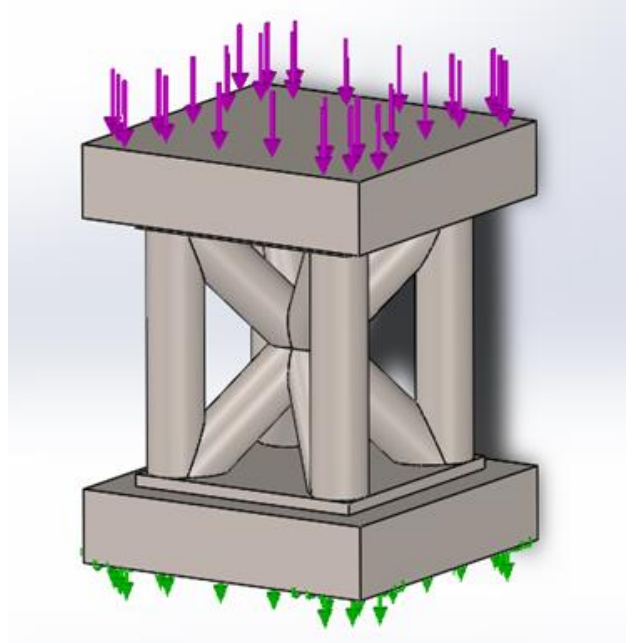

(b)

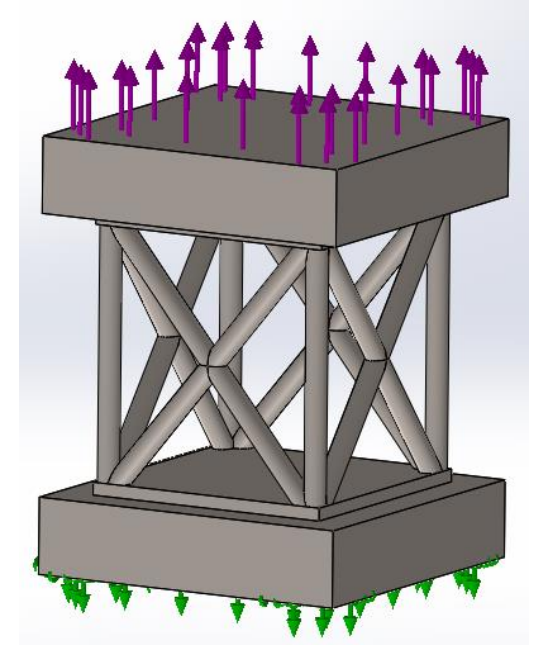

Figure 3. Tension and compression FEA set-up for both (a) BCC and (b) FCC models.

This final FEA was performed after some preliminary testing and 4000N was chosen so that each analysis was testing within the elastic region. The load was also chosen due to the FEA being performed in SolidWorks being a linear, static analysis so remaining within the elastic region of the model is imperative. The mesh used in this analysis was a curvature based mesh, with a maximum and minimum element size of $0.858 \mathrm{~mm}$ and $0.043 \mathrm{~mm}$ respectively. The minimum number of elements in a circle used was 8 and the element growth size ratio was 1.6. 
The displacement results from the FEA were analyzed and the highest displacement result per simulation was used to calculate the specimen's stiffness. This is due to all the displacement being within the lattice model because the plates in either side of the lattice are extremely stiff and will not deform significantly to influence the analysis. Now knowing force and displacement for each specimen, the stiffness can be calculated using

$$
k=\frac{F}{d}
$$

where $F$ is the force applied, and $d$ is the displacement result in each FEA performed, both in compression and tension. As stated, the lattice structure's material was edited to a custom material. This material was configured to be as close to the properties of EOS MS1, or maraging steel [14] since this was the material to be used in fabrication of the specimens. Table 1 shows the mechanical properties used for FEA.

\begin{tabular}{|c|c|}
\hline Material property & Value \\
\hline Tensile strength $(\mathrm{MPa})$ & 2000 \\
\hline Yield strength $(\mathrm{MPa})$ & 1900 \\
\hline $\begin{array}{c}\text { Thermal coefficient of } \\
\text { expansion }\left(\mathrm{K}^{-1}\right)\end{array}$ & $1.3 \times 10^{-5}$ \\
\hline $\begin{array}{c}\text { Thermal conductivity } \\
\left(\mathrm{Wm}^{-1} \mathrm{~K}^{-1}\right)\end{array}$ & 20 \\
\hline Specific heat $\left(\mathrm{J} \mathrm{kg}^{-1} \mathrm{~K}^{-1}\right)$ & 450 \\
\hline Elastic modulus $(\mathrm{GPa})$ & 180 \\
\hline Poison's ratio & 0.28 \\
\hline Shear modulus $(\mathrm{GPa})$ & 79 \\
\hline Mass density $\left(\mathrm{kg} \mathrm{m}^{-3}\right)$ & 8000 \\
\hline
\end{tabular}

Table 1. Properties used in FEA to represent EOS MS1.

Figure 4 shows a screenshot of the displacement in the assembly after the simulation. Table 2 shows all diameters used with the associated weight reduction from a solid cube. 

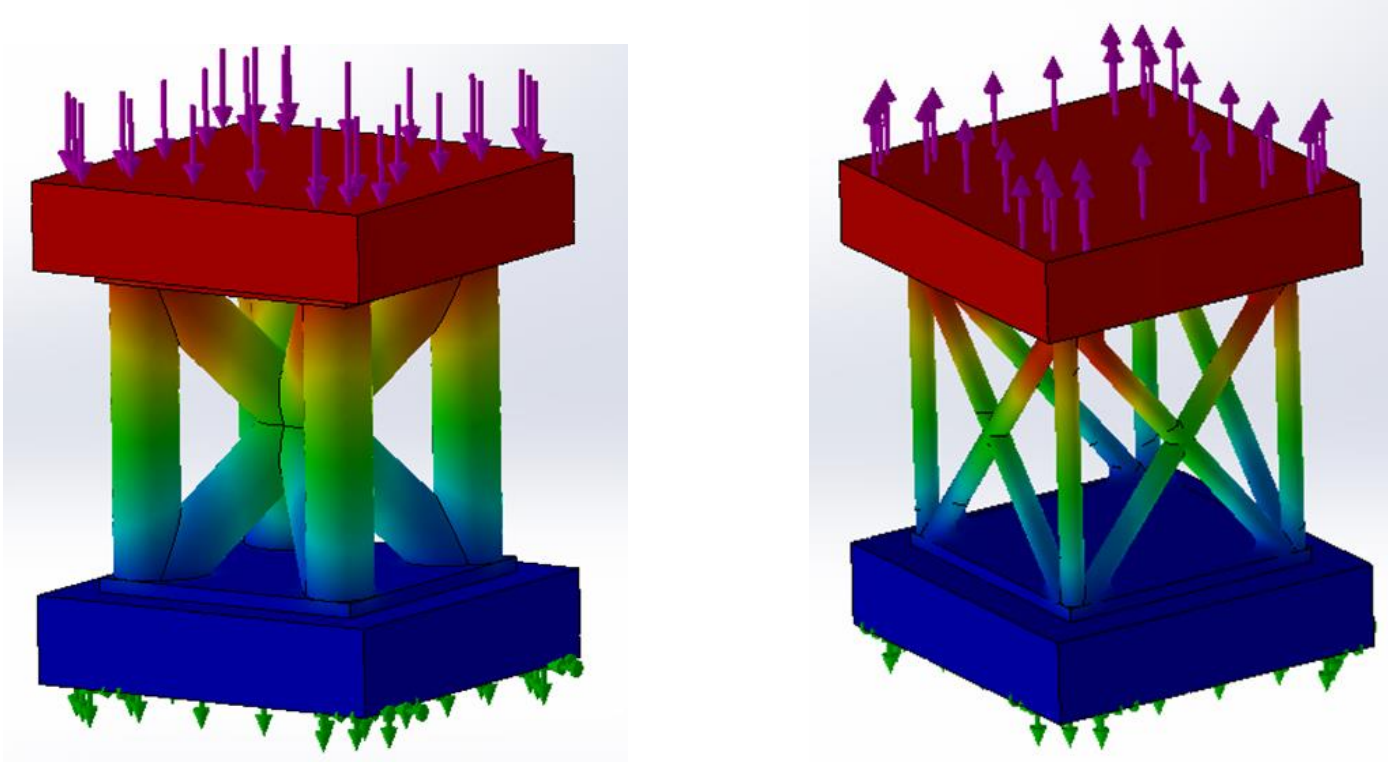

Figure 4. Displacement in both tension and compression simulations.

\begin{tabular}{|c|c|c|}
\hline Unit Cell & $\begin{array}{c}\text { Strut diameter } \\
(\mathrm{mm})\end{array}$ & $\begin{array}{c}\text { Weight reduction } \\
(\%)\end{array}$ \\
\hline \multirow{4}{*}{ FCC } & 0.855 & 88.18 \\
\cline { 2 - 3 } & 1.215 & 77.14 \\
\cline { 2 - 3 } & 1.51 & 65.97 \\
\cline { 2 - 3 } & 1.77 & 54.94 \\
\hline \multirow{4}{*}{ BCC } & 1.27 & 88.18 \\
\cline { 2 - 3 } & 1.83 & 77.01 \\
\cline { 2 - 3 } & 2.30 & 65.97 \\
\cline { 2 - 3 } & 2.75 & 55.06 \\
\hline
\end{tabular}

Table 2. Listed strut diameters for each topology with associated weight reduction.

An FEA was also performed with this same set-up using a solid cube in place of the lattice structure to compare the stiffness of the lattice specimens to a solid cube stiffness. 


\section{B. Fabrication}

Once all specimens were modeled and an FEA was performed, all models were saved as a stereolithography, .stl, file. The files were first upload to Materialise Magics software, a computer-aided engineering and design software. This software was used to properly orient each part for the building process as well as to generate the support needed for each part. Figure 5 shows the properly printing orientation for each specimen with the z-direction being the direction each part would be printed, layer-by-layer, from start to finish.
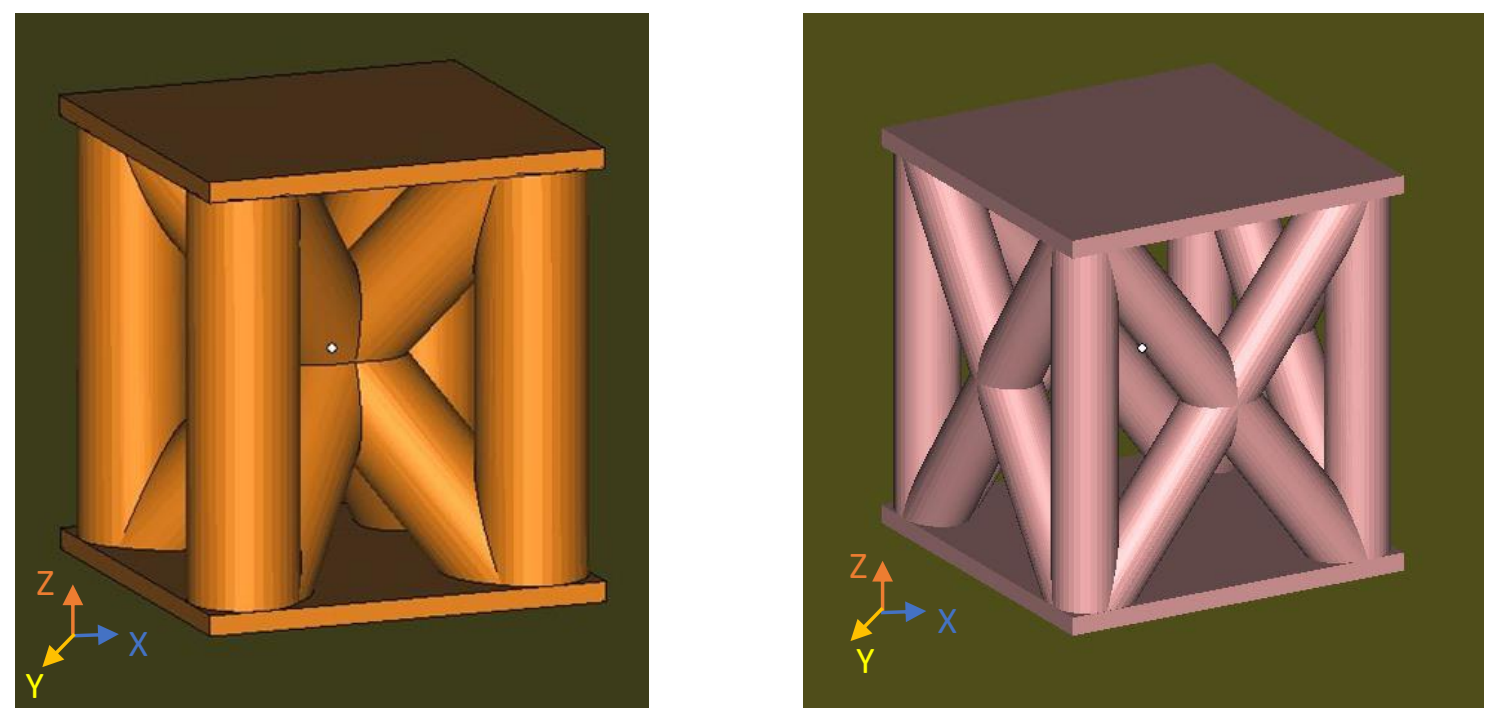

Figure 5. Orientation of BCC and FCC specimens.

Figure 6 shows the support generation between the part and build plate that would be used in printing. The offset used between part and build plate, or the height of the support material, was $5 \mathrm{~mm}$. 

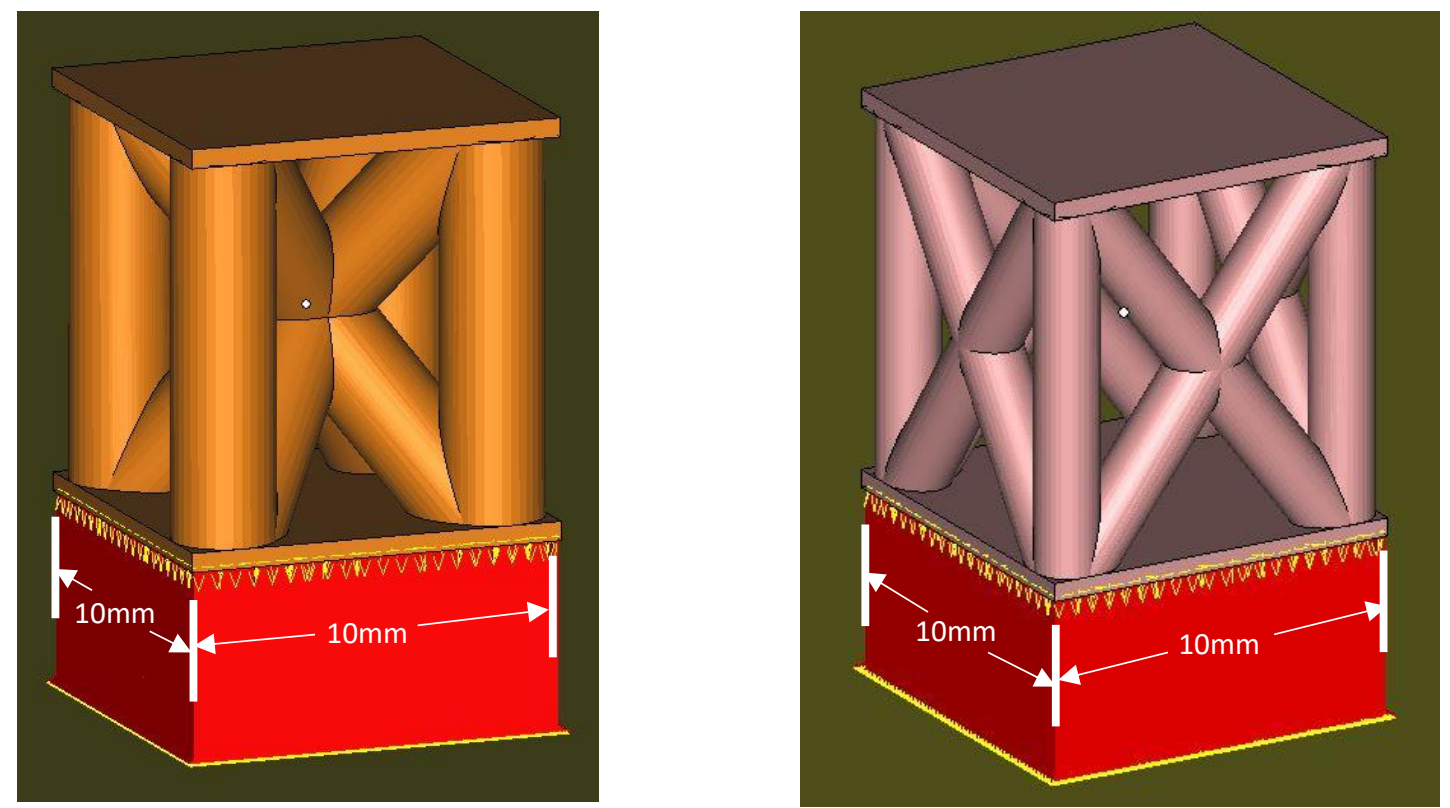

Figure 6. Supports generated for BCC and FCC specimens.

Support structures are needed when using additive manufacturing technology in metal material to connect each part to a build plate. If a part is built directly connected to a build plate, you will cut into the part during removal of the specimen from build plate and could damage the specimen overall.

The software SliView was then used to slice each specimen and support into layers. SliView allows the user to select the layer thickness the user would like to slice each part into. This is so that when reading in the parts into the EOS M270, it will be able to read each part and all layers properly. Based on the model, powder being used, and machine parameters, the layer thickness used in this study for all parts was $40 \mu \mathrm{m}$. Finally, with all parts sliced into the correct layer thickness, the parts were loaded into the EOS M270 software to be properly positioned and duplicated. All parts were set-up with default EOS_DirectPart and EOS_Support scanning parameters.

After the build finished, a vertical bandsaw was used to cut parts from the build plate so that post-build finishing could be done. The part supports were removed using either a CNC 
milling process or using a hand grinder. CNC milling was used only for the first iteration of specimens while for the second and third iterations, only a hand grinder was necessary.

\section{Testing}

When all parts were cleaned of supports, mechanical testing was performed on each specimen to determine stiffness response in comparison to the FEA stiffness. Figure 7 and shows the first iteration printed part for both FCC and BCC specimens.

(a)

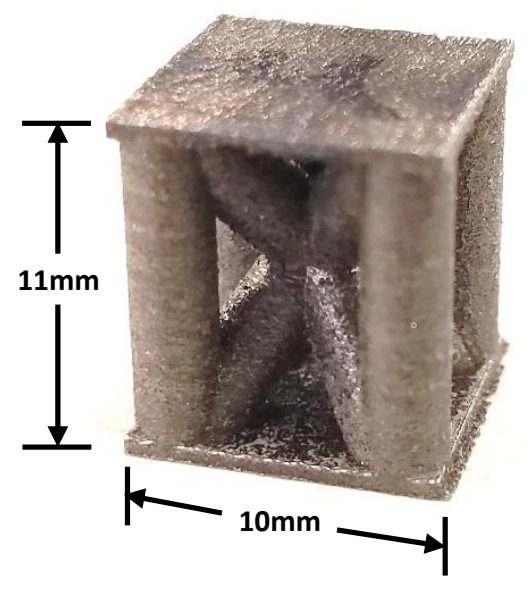

(b)

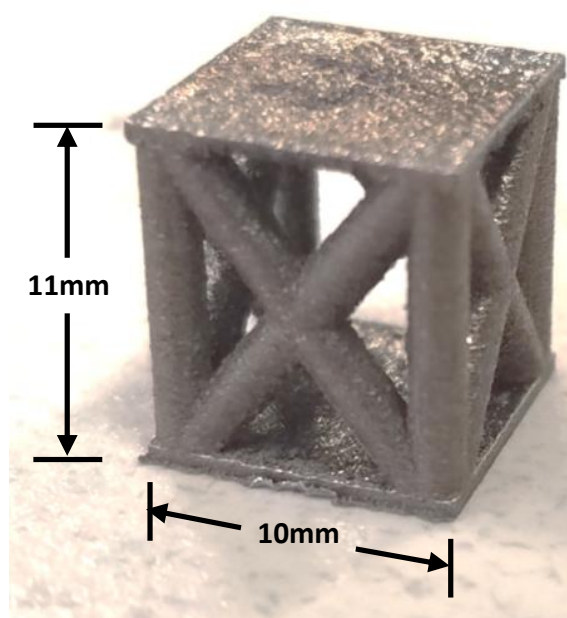

Figure 7. Post-machining of printed first iteration (a) BCC and (b) FCC specimens.

Each specimen was modeled to be $11 \mathrm{~mm} \times 10 \mathrm{~mm} \times 10 \mathrm{~mm}$. The lattice was contained within a uniform $1000 \mathrm{~mm}^{3}$ cube with the addition of $0.5 \mathrm{~mm}$ thick plates on both bottom and top sides. The plates were added to help the fixtures evenly distribute the load over the lattice during compression loading. As shown in Figure 8. the bottom plate was machined of all support on the underside. 


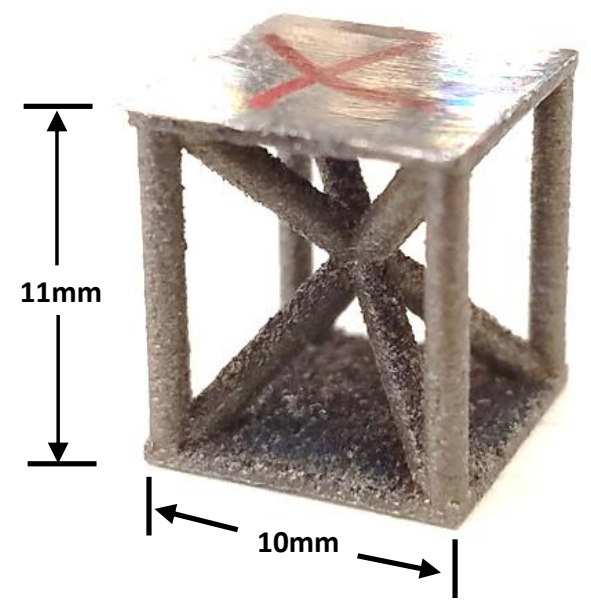

Figure 8. Machined surface of first iteration specimens.

The second iteration of specimens added extra mass to each end of the lattice, which facilitated easier specimen gripping during mechanical testing. Figure 9 show the model of these parts and Figure 10 shows the printed part after removing supports.

(a)
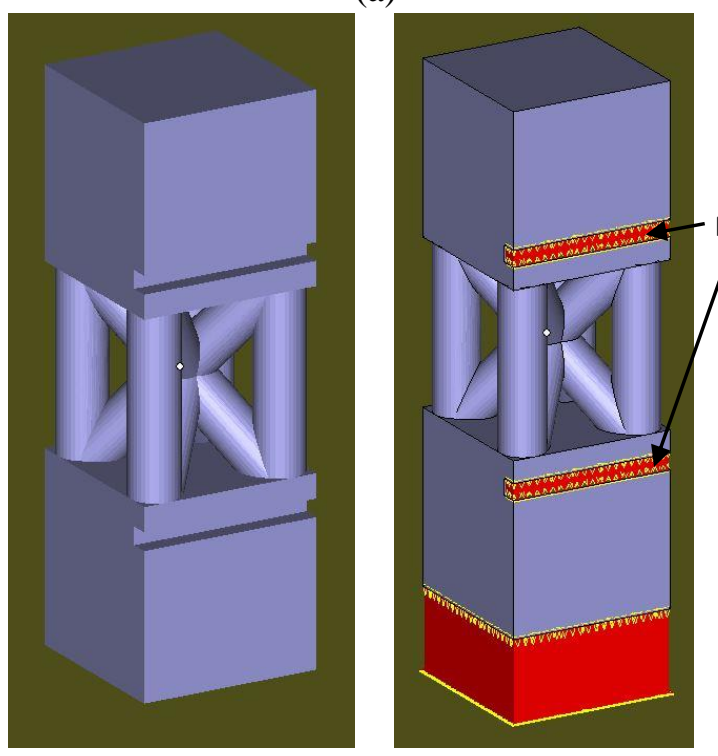

(b)
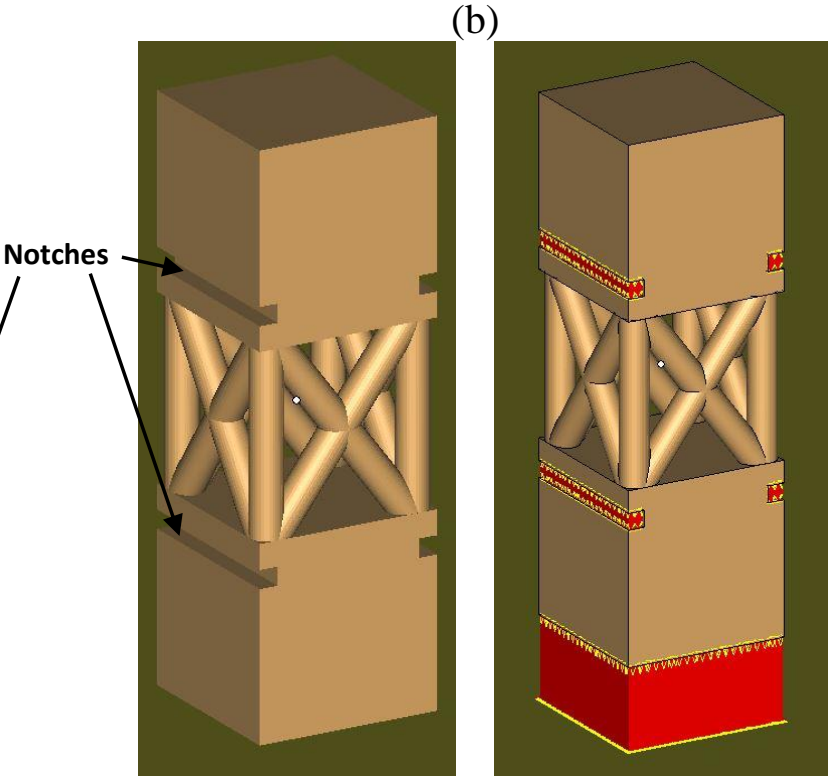

Figure 9. Second iteration of (a) BCC and (b) FCC specimens with additional masses and support generation. 
(a)

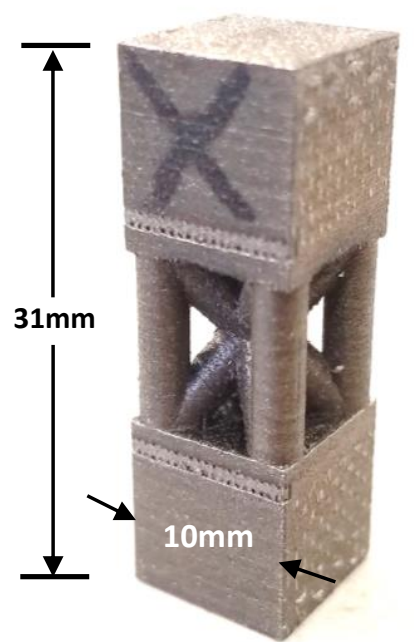

(b)

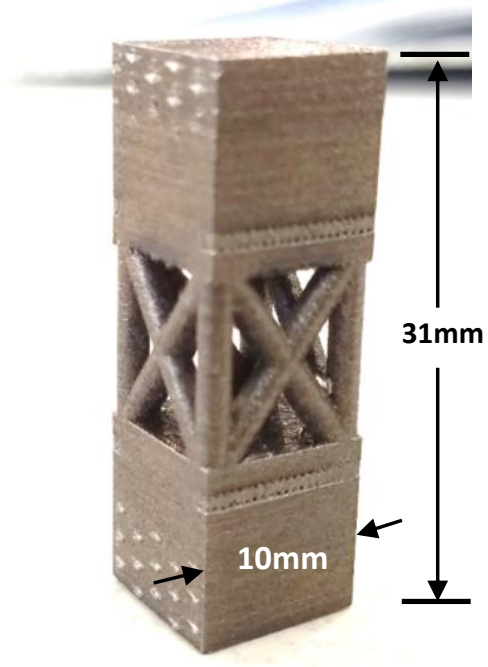

Figure 10. Printed second iteration (a) BCC and (b) FCC specimens.

$10 \mathrm{~mm}$ were added to the $0.5 \mathrm{~mm}$ plates from the first specimens. This makes for an overall grip section length of $10.5 \mathrm{~mm}$ and a total height in specimen of $31 \mathrm{~mm}$. The addition of the mass was to enable either testing in compression or tension of the lattice structures. The additional masses would allow the student to use gripping tools during testing in the Intron 5569A. Also, small $1 \mathrm{~mm}$ notches were added to these masses as shown in Figure 9. This was to enable the use of an extensometer to more accurately measure the displacement between top and bottom faces in the lattice during testing.

The third and final iteration of specimens added fillets to the connections of struts to the added masses. Three fillets sizes were modeled per specimen: $0.5 \mathrm{~mm}, 1.0 \mathrm{~mm}$, and $1.5 \mathrm{~mm}$. The reason for the addition is to decrease the sudden change in cross-sectional area between struts and the additional mass sections. As research shows, stress concentrations are greatest at sharp corners. If the rapid changes in geometry at this connection between struts and additional mass can be softened or less sudden, then the load can be applied more uniformly in the lattice rather than being heavily concentrated at these sharp edges. With the addition of fillets at these 
connections, it is expected that the effective modulus and stiffness of the unit cell will increase, more specifically it will increase in tension. Figure 11a and Figure 11b shows the model of each fillet.

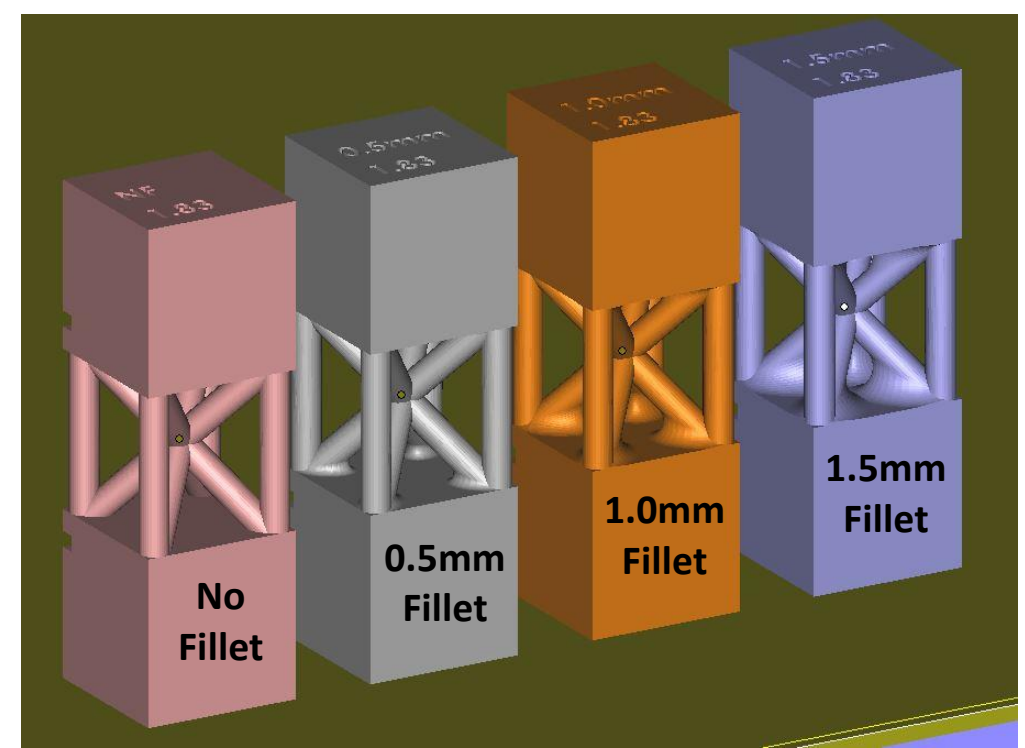

Figure 11a. BCC modeled specimens with varying fillet sizes.

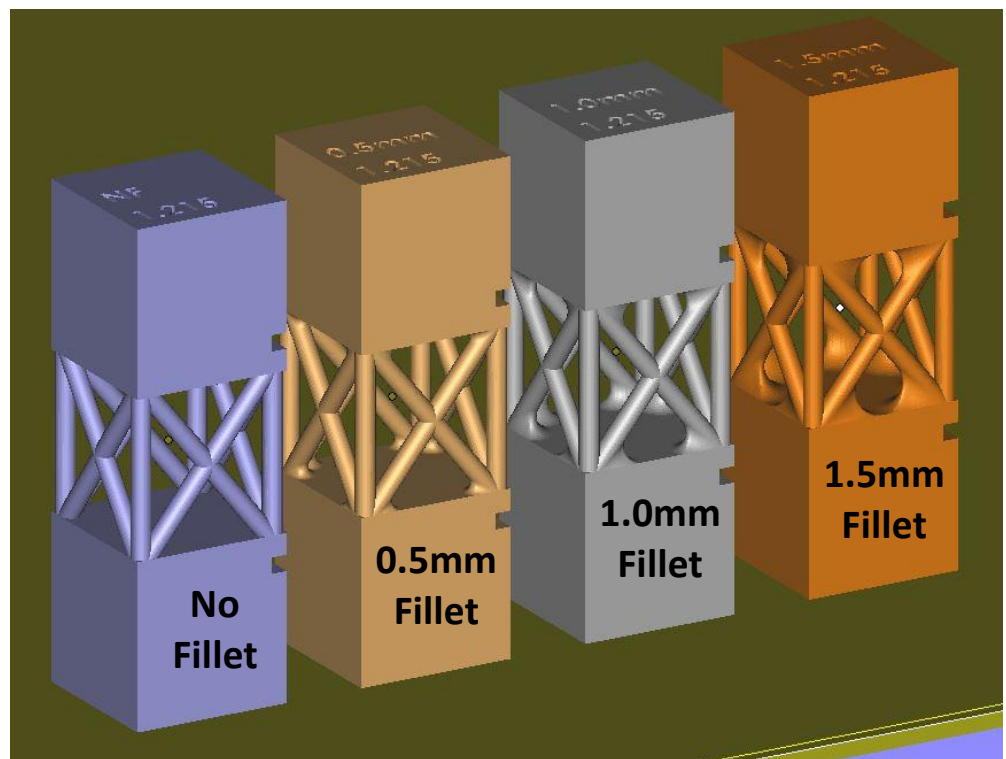

Figure 11b. FCC modeled specimens with varying fillet sizes.

Figure 12a and Figure 12b shows a visual comparison of each fillet after printing and post hand grinding support from each specimen. 


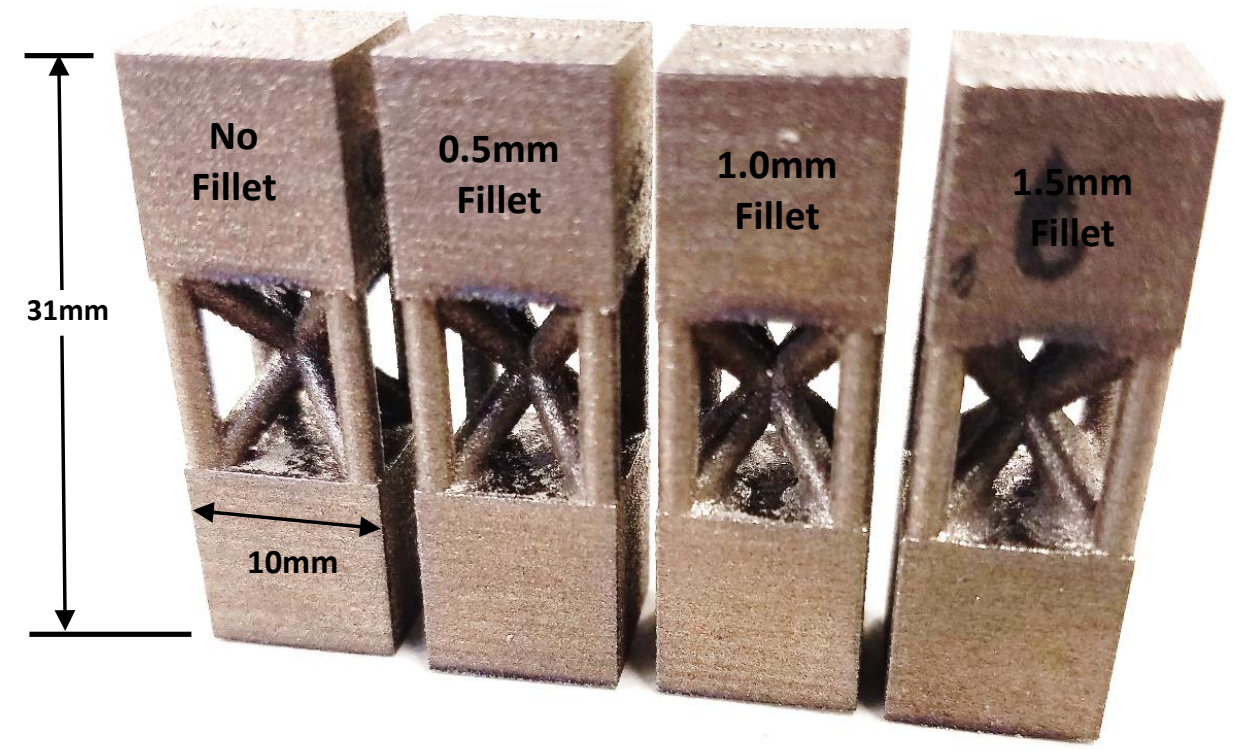

Figure 12a. BCC printed specimens with varying fillet sizes post grinding.

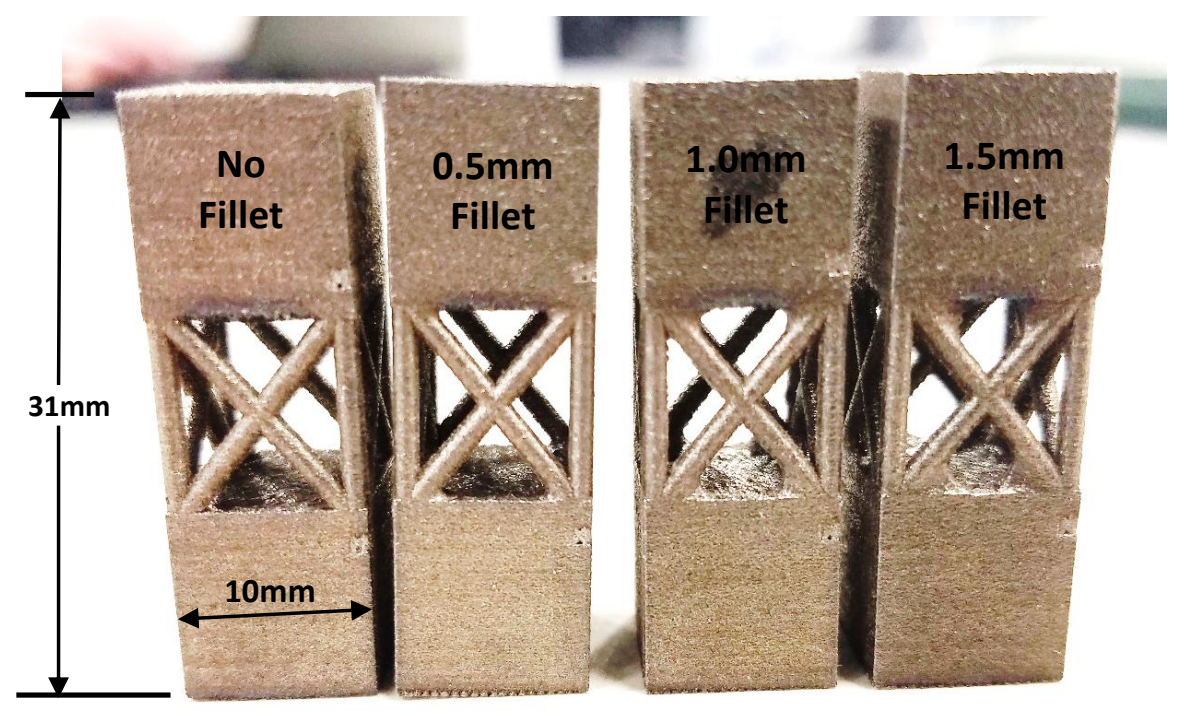

Figure 12b. FCC printed specimens with varying fillet sizes post grinding.

With fillets, you add mass back to the unit cell, which yields a different mass reduction from a solid cube than the first and second iterations of specimens printed. But, with high stress concentrations at sharp corners, such as the strut connections on the top and bottom of the lattice unit cell, the addition of fillets in varying sizes will decrease the corner sharpness which would effectively decrease stress concentration at the connections. This should increase the stiffness 
and effective modulus of the unit cell. This study is to test this theory by testing in compression and tension these specimens, calculate the stiffness response and compare results across fillet and non-fillet parts. This study is unique in that no other study has looked at the effects of an addition of fillets to unit cell connections within a lattice structure. But other studies have been performed pertaining specifically to lattice structures, such as Yan and Hao [5] who look at the effects of increasing the number of struts inside the unit cell and concluding as the strut size increases and the mass reduction from a solid decreases that the overall effective strength increases, Contuzzi [7] who concluded that by increasing the number of vertical struts inside the unit cell a greater loading capacity is achieved. Studies specifically analyzing the effects of stress concentrations, such as the investigation of notches and fillets being introduced to a flat plate and the resulting elastic and plastic stress concentrations [25] and investigation of different discontinuities, such as a hole or sharp corner, and how this differ to a uniform cross-section during testing using photo elastic methods. Lastly studies focusing on the effects of fillets, such as looking at the amount of deflection that occurs in changing the fillet sizing within a spur gear [22] and the effects of different fillet configurations within an airfoil on boundary layer growth that occurs from shock waves impacting a low-momentum fluid [23]. 


\section{RESULTS AND DISCUSSION}

Each specimen was modeled to yield a certain weight reduction in both the face-centered cells (FCC) and the body-centered cells (BCC) from a solid cube. Once strut diameters were chosen for the FCC and BCC models, a finite element analysis (FEA) was performed in SolidWorks to calculate the compressive stiffness in each model. Table 3 shows FEA stiffness results for all FCC and BCC specimens as well as a solid cube stiffness.

\begin{tabular}{|c|c|c|c|}
\hline Unit cell & $\begin{array}{c}\text { Strut diameter } \\
(\mathrm{mm})\end{array}$ & $\begin{array}{c}\text { Weight reduction } \\
(\%)\end{array}$ & $\begin{array}{c}\text { FEA compression } \\
\text { stiffness }(\mathrm{kN} / \mathrm{mm})\end{array}$ \\
\hline \multirow{4}{*}{ FCC } & 0.855 & 88.2 & 75.2 \\
\cline { 2 - 4 } & 1.215 & 77.1 & 156.5 \\
\cline { 2 - 4 } & 1.510 & 66.0 & 247.0 \\
\cline { 2 - 4 } & 1.770 & 54.9 & 346.3 \\
\hline \multirow{4}{*}{ BCC } & 1.270 & 88.1 & 115.0 \\
\cline { 2 - 4 } & 1.830 & 77.0 & 252.7 \\
\cline { 2 - 4 } & 2.300 & 66.1 & 418.5 \\
\cline { 2 - 4 } & 2.750 & 55.1 & 622.2 \\
\hline Solid & - & - & 1888.6 \\
\hline
\end{tabular}

Table 3. Calculated stiffness' from FEA load and displacement results.

BCC models yielded a greater FEA stiffness when compared to FCC models with roughly the same weight reduction. The FEA performed was a linear, static analysis. The mesh used in this analysis was a curvature based mesh, with a maximum and minimum element size of $0.858 \mathrm{~mm}$ and $0.043 \mathrm{~mm}$ respectively. The minimum number of elements in a circle used was 8 and the element growth size ratio was 1.6. Both topologies have increasing stiffness with increasing strut diameter, which makes sense since more mass is present in the unit cell and behaves closer to a solid cube.

Only a linear, static analysis was performed for simplicity and this report mainly focusing on the physical behavior of the lattice specimens. Other analysis' such as nodal analysis or buckling analysis can be performed but these analysis' would not prove a useful comparison since the majority of the report analyzed the testing of lattice specimens within the elastic region 
where no buckling would occur. Also, nodal analysis will average stress and strain results instead of not-averaging them. For example, in nodal analysis, one node is shared by several elements and each element calculates different stresses and strains at the shared node. These values from all adjacent elements are then averaged to obtain a single value. This method of stress and strain averaging produces averaged results. In elemental analysis, the adjacent element stresses and strain are not averaged because the averaging is done internally within the same element only.

Having a model and stiffness for each specimen, the first iteration of parts were fabricated in an EOS M270 direct metal laser sintering (DMLS) machine. After the build had completed, each part was removed of build support via CNC milling and cleared of all loose powder inside the lattice unit cell structure. Figure 13 shows surface quality of a printed part.

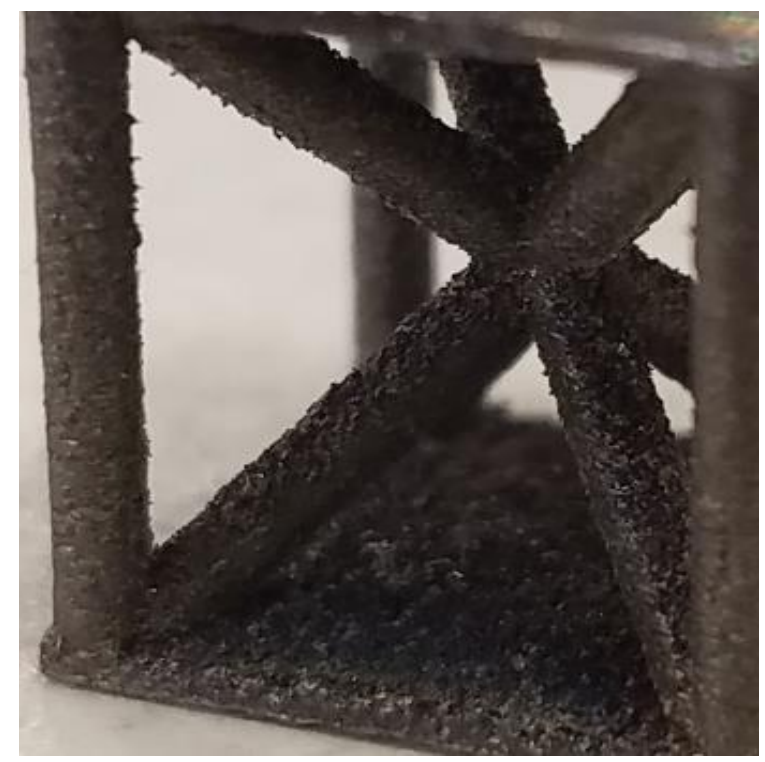

Figure 13. Close-up picture of surface quality in printed specimens.

All parts had rough struts and surfaces, mainly on downward facing surfaces. This is to be expected since all supports generated for the overhanging internal geometry were deleted as they would be impossible to remove. These overhangs had the most partially sintered material in the unit cell in all specimens. 
After post-processing, the first iteration of specimens was tested in compression in the Instron 5569A Dual Column Testing System. Specimen stiffness was calculated from the resulting load $(\mathrm{N})$ verses displacement $(\mathrm{mm})$ plot from the Instron 5569A. Since an extensometer could not be applied to the specimen, displacement was calculated from crosshead displacement inside the Instron 5569A. A sample resulting plot from BCC $1.83 \mathrm{~mm}$ strut diameter specimen is shown in Figure 14.

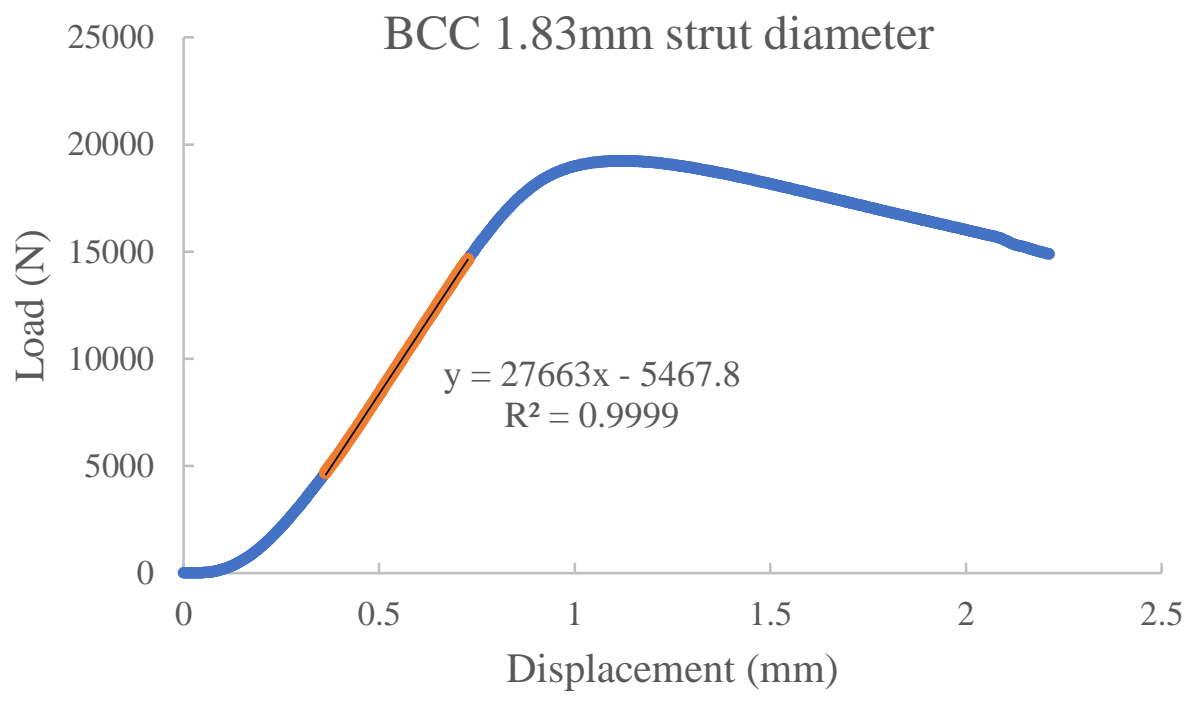

Figure 14. Sample result plot from BCC 1.83mm specimen.

The blue line is the result from the entire test in the Instron of the specimen. Loading was applied until the specimen was past the elastic region and starting to yield. The orange line is selected data to average and fit with a trendline in Excel; the calculated slope being the resulting stiffness for that particular specimen. The compression testing stiffness of 3 specimens were averaged and these results are shown in Table 4 compared to FEA compression stiffness. 


\begin{tabular}{|c|c|c|c|}
\hline Unit cell & $\begin{array}{c}\text { Strut diameter } \\
(\mathrm{mm})\end{array}$ & $\begin{array}{c}\text { Compression } \\
\text { testing stiffness } \\
(\mathrm{kN} / \mathrm{mm})\end{array}$ & $\begin{array}{c}\text { Testing stiffness } \\
\text { to FEA stiffness } \\
(\%)\end{array}$ \\
\hline \multirow{4}{*}{ FCC } & 0.855 & 12.0 & 16.1 \\
\cline { 2 - 4 } & 1.215 & 21.6 & 13.9 \\
\cline { 2 - 4 } & 1.510 & 28.4 & 11.5 \\
\cline { 2 - 4 } BCC & 1.770 & 30.3 & 8.79 \\
\cline { 2 - 4 } & 1.270 & 17.2 & 15.0 \\
\cline { 2 - 4 } & 1.830 & 27.7 & 11.0 \\
\cline { 2 - 4 } & 2.300 & 37.2 & 8.94 \\
\hline
\end{tabular}

Table 4. Percent stiffness of tested specimens to FEA models.

The first iteration of specimen yielded poor stiffness results when compared to the FEA performed in SolidWorks. All testing stiffness' were lower than 20\% the stiffness calculated in SolidWorks. The results show that while increasing strut diameter increases unit cell stiffness, the comparison to FEA decreases. The lowest stiffness comparisons were in the highest strut diameters for FCC and BCC specimens. One cause of low testing results compared to FEA came from the fracturing of the $0.5 \mathrm{~mm}$ plates during testing. Figures $15 \mathrm{a}$ and $15 \mathrm{~b}$ shows BCC and FCC specimens post testing.

(a)

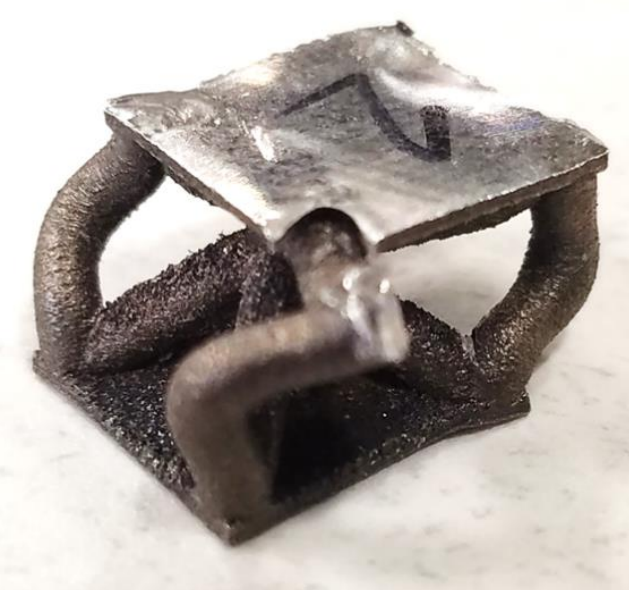

(b)

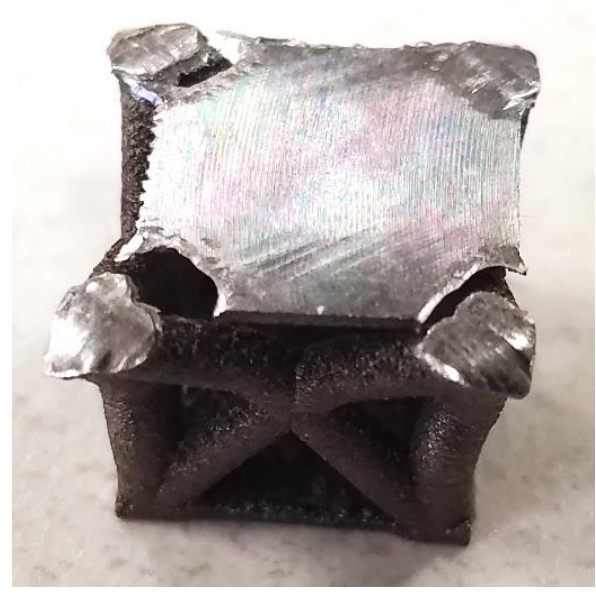

Figure 15. Fracturing of base plates in both (a) BCC and (b) FCC specimens. 
The thin plates were influencing the results by causing the load to be carried in the plates as well as the lattice structures, when the target was to only have load carried in the lattice. This would decrease maximum load results in each lattice tested. Also with the load cell mounted in the crosshead of the machine, the load would have to travel through multiple components before being applied to the lattice structures themselves: through the load cell, several adaptors and pins, the compression fixture, and then into the lattice structures. This could influence total displacement in the lattice structures since some small deflection could occur in these other components. Finally, it was noticed that both compression fixtures used in testing had slight impressions in them from the specimens after testing. The compression fixtures material hardness was later discovered to be less than that of EOS MS1. This also influenced the maximum loading results as well as total displacement in the lattice structure in relation to crosshead displacement.

Influenced by the low results and failure of the first specimens, the second iteration of specimens were modeled with additional mass on the top and bottom of the lattice. $10 \mathrm{~mm}$ of additional solid mass was added to both the top and bottom $0.5 \mathrm{~mm}$ plate, making for a $10.5 \mathrm{~mm}$ solid section on either side of the lattice. This was to allow grips to be used to hold the specimen in place during testing and would enable testing in either compression or tension. Also, the addition of a $1 \mathrm{~mm}$ notch in the top and bottom mass sections would allow an extensometer to be placed and used during testing. The extensometer would yield a more accurate displacement reading of the lattice structure during testing.

After the second iteration of specimens were built, the strut diameters for each specimen were measured and averaged using digital calipers. These measured strut diameters were compared to the modeled diameters. This comparison is shown in Table 5. 


\begin{tabular}{|c|c|c|c|}
\hline Unit cell & $\begin{array}{c}\text { Modeled strut } \\
\text { diameter } \\
(\mathrm{mm})\end{array}$ & $\begin{array}{c}\text { Measured } \\
\text { strut diameter } \\
(\mathrm{mm})\end{array}$ & $\begin{array}{c}\text { Difference between } \\
\text { measured to modeled } \\
\text { strut diameter }(\%)\end{array}$ \\
\hline \multirow{4}{*}{ FCC } & 0.855 & 0.80 & -6.4 \\
\cline { 2 - 4 } & 1.215 & 1.12 & -7.8 \\
\cline { 2 - 4 } & 1.510 & 1.48 & -2.3 \\
\cline { 2 - 4 } BCC & 1.770 & 1.75 & -1.4 \\
\cline { 2 - 4 } & 1.270 & 1.21 & -4.7 \\
\cline { 2 - 4 } & 1.830 & 1.75 & -4.4 \\
\cline { 2 - 4 } & 2.300 & 2.24 & -2.6 \\
\hline
\end{tabular}

Table 5. Measured verses modeled strut diameter comparison.

All measured strut diameters of specimens after being built were smaller than modeled diameters. The best comparison between measured and modeled strut diameters came in the higher diameters; the largest printed diameter in the FCC specimens, $1.77 \mathrm{~mm}$ struts, and the second largest in the BCC specimens, $2.3 \mathrm{~mm}$ struts, yielded the least percent difference to what was modeled per topology.

The second iteration of specimens were also weighted and compared to weight calculations in SolidWorks using mass properties. These weight comparisons of the second iteration are shown in Table 6.

\begin{tabular}{|c|c|c|c|c|}
\hline Unit cell & $\begin{array}{c}\text { Measured } \\
\text { strut diameter } \\
(\mathrm{mm})\end{array}$ & $\begin{array}{c}\text { SolidWorks } \\
\text { weight } \\
\text { calculation }(\mathrm{g})\end{array}$ & $\begin{array}{c}\text { Measured } \\
\text { weight } \\
(\mathrm{g})\end{array}$ & $\begin{array}{c}\text { Measured weight to } \\
\text { SolidWorks } \\
\text { prediction }(\%)\end{array}$ \\
\hline \multirow{4}{*}{ FCC } & 0.80 & 17.56 & 18.0 & 102.7 \\
\cline { 2 - 5 } & 1.12 & 18.44 & 18.7 & 101.2 \\
\cline { 2 - 5 } & 1.48 & 19.33 & 19.3 & 99.7 \\
\cline { 2 - 5 } & 1.75 & 20.22 & 19.6 & 97.0 \\
\hline \multirow{4}{*}{ BCC } & 1.21 & 17.57 & 18.3 & 104.0 \\
\cline { 2 - 5 } & 1.75 & 18.46 & 19.2 & 103.9 \\
\cline { 2 - 5 } & 2.24 & 19.33 & 20.0 & 103.6 \\
\cline { 2 - 5 } & 2.66 & 20.22 & 20.9 & 103.4 \\
\hline
\end{tabular}

Table 6. Weight comparison between modeled and printed second iteration specimens.

All but two specimens, FCC $1.48 \mathrm{~mm}$ strut and $1.75 \mathrm{~mm}$ strut, were measured to be heavier than calculated in SolidWorks. The largest increase in weight was in the BCC $1.21 \mathrm{~mm}$ strut with 
$4.0 \%$ increase. The largest decrease in weight was in the FCC $1.75 \mathrm{~mm}$ strut with a $3.0 \%$ decrease.

To most accurately compare testing data to FEA data, the FEA was reran with all the measured strut diameters of printed specimens. New FEA compression stiffness' corresponding to the measured strut diameters and a comparison to the original FEA of the modeled specimens is shown in Table 7.

\begin{tabular}{|c|c|c|c|c|c|}
\hline Unit cell & $\begin{array}{c}\text { Modeled } \\
\text { strut } \\
\text { diameter } \\
(\mathrm{mm})\end{array}$ & $\begin{array}{c}\text { Modeled FEA } \\
\text { compressive } \\
\text { stiffness } \\
(\mathrm{kN} / \mathrm{mm})\end{array}$ & $\begin{array}{c}\text { Measured } \\
\text { strut } \\
\text { diameter } \\
(\mathrm{mm})\end{array}$ & $\begin{array}{c}\text { Measured FEA } \\
\text { compressive } \\
\text { stiffness } \\
(\mathrm{kN} / \mathrm{mm})\end{array}$ & $\begin{array}{c}\text { Original FEA } \\
\text { to new FEA } \\
\text { stiffness (\%) }\end{array}$ \\
\hline \multirow{4}{*}{ FCC } & 0.855 & 75.2 & 0.80 & 65.1 & -13.4 \\
\cline { 2 - 6 } & 1.215 & 156.5 & 1.12 & 130.9 & -16.3 \\
\cline { 2 - 6 } & 1.510 & 247.0 & 1.48 & 234.2 & -5.2 \\
\cline { 2 - 6 } & 1.770 & 346.3 & 1.75 & 333.6 & -3.7 \\
\hline \multirow{4}{*}{ BCC } & 1.270 & 115.0 & 1.21 & 103.3 & -10.2 \\
\cline { 2 - 6 } & 1.830 & 252.7 & 1.75 & 228.3 & -9.6 \\
\cline { 2 - 6 } & 2.300 & 418.5 & 2.24 & 393.3 & -6.0 \\
\cline { 2 - 6 } & 2.750 & 622.2 & 2.66 & 571.6 & -8.1 \\
\hline
\end{tabular}

Table 7. Measured verses modeled FEA compression stiffness comparison.

As expected, with measured strut diameter being less than the modeled, the FEA also decreases since the FEA being performed is a linear, static FEA.

The second iteration of specimens were modeled to allow testing in either compression or tension. Therefore, an FEA in tension for all specimens was performed. These tensile FEA results are shown in Table 8 . 


\begin{tabular}{|c|c|c|}
\hline Unit cell & $\begin{array}{c}\text { Measured } \\
\text { strut diameter } \\
(\mathrm{mm})\end{array}$ & $\begin{array}{c}\text { FEA tensile } \\
\text { stiffness } \\
(\mathrm{kN} / \mathrm{mm})\end{array}$ \\
\hline \multirow{4}{*}{ FCC } & 0.80 & 65.5 \\
\cline { 2 - 3 } & 1.12 & 131.9 \\
\cline { 2 - 3 } & 1.48 & 235.4 \\
\cline { 2 - 3 } BCC & 1.75 & 336.1 \\
\cline { 2 - 3 } & 1.21 & 103.7 \\
\cline { 2 - 3 } & 1.75 & 229.1 \\
\cline { 2 - 3 } & 2.24 & 394.5 \\
\hline
\end{tabular}

Table 8. Tensile stiffness calculated from a FEA in SolidWorks.

The second iteration testing stiffness was calculated differently than in the first iteration. As stated, the first iteration stiffness was calculated from the load verses displacement plot. The second iteration stiffness was calculated using the effective modulus result from testing for each specimen. Below is the derivation used to calculate stiffness from effective modulus.

$$
\begin{gathered}
E=\frac{\sigma}{\varepsilon} \\
E=\frac{F / A}{\Delta L / L} \\
F=E\left(\frac{\Delta L \cdot A}{L}\right) \\
k=\frac{F}{\Delta L} \\
E\left(\frac{\Delta L \cdot A}{L}\right) \\
\Delta L
\end{gathered}
$$

$E$ is calculated effective modulus from the resulting true stress, $\sigma$, verses true strain, $\varepsilon$, plot, $A$ is the cross-sectional area of each lattice specimen, $100 \mathrm{~mm}^{2}$, and $L$ is the gage length of the lattice 
specimen, $10 \mathrm{~mm}$. What this derivation shows is that the simple conversion between effective modulus and stiffness is only gage length. This can be useful since modulus is a more versatile mechanical property and more often used in analysis. The true strain was calculated from the extensometer displacement.

For the second iteration of specimens, all were tested within the elastic region. Stiffness results for both FCC and BCC specimens from the second iteration are shown in Table 9. Stiffness results were calculated from only 1 specimen of each topology and strut diameter configuration.

\begin{tabular}{|c|c|c|c|}
\hline Unit cell & $\begin{array}{c}\text { Measured } \\
\text { strut diameter } \\
(\mathrm{mm})\end{array}$ & $\begin{array}{c}\text { Measured } \\
\text { tensile stiffness } \\
(\mathrm{kN} / \mathrm{mm})\end{array}$ & $\begin{array}{c}\text { Measured } \\
\text { compressive } \\
\text { stiffness } \\
(\mathrm{kN} / \mathrm{mm})\end{array}$ \\
\hline \multirow{4}{*}{ FCC } & 0.80 & 141.1 & 133.4 \\
\cline { 2 - 4 } & 1.12 & 199.4 & 521.5 \\
\cline { 2 - 4 } & 1.48 & 336.8 & 693.8 \\
\hline \multirow{3}{*}{ BCC } & 1.75 & 606.9 & 536.5 \\
\cline { 2 - 4 } & 1.21 & 184.1 & 142.4 \\
\cline { 2 - 4 } & 1.75 & 335.1 & 288.2 \\
\cline { 2 - 4 } & 2.24 & 621.8 & 530.7 \\
\hline
\end{tabular}

Table 9. Compressive and tensile stiffness in each tested specimen.

With increasing strut diameter yields an increase in stiffness. This agrees with previously mentioned studies performed by Yan and Hao [5], Young [6], and Contuzzi [7] as well as the first iteration of specimens. Comparisons to both tensile and compressive FEA stiffness' are shown in Table 10. 


\begin{tabular}{|c|c|c|c|}
\hline Unit cell & $\begin{array}{c}\text { Measured } \\
\text { strut diameter } \\
(\mathrm{mm})\end{array}$ & $\begin{array}{c}\text { Measured tensile } \\
\text { stiffness to FEA tensile } \\
\text { stiffness (\%) }\end{array}$ & $\begin{array}{c}\text { Measured compressive } \\
\text { stiffness to FEA } \\
\text { compressive stiffness (\%) }\end{array}$ \\
\hline \multirow{4}{*}{ FCC } & 0.80 & 215.6 & 205.0 \\
\cline { 2 - 4 } & 1.12 & 151.1 & 398.3 \\
\cline { 2 - 4 } & 1.48 & 143.1 & 296.2 \\
\cline { 2 - 4 } BCC & 1.75 & 180.5 & 160.8 \\
\cline { 2 - 4 } & 1.21 & 177.5 & 137.9 \\
\cline { 2 - 4 } & 1.75 & 146.3 & 126.2 \\
\cline { 2 - 4 } & 2.24 & 157.6 & 134.9 \\
\hline
\end{tabular}

Table 10. Tension and compression testing stiffness' compared to FEA results.

All stiffness testing results were greater than that of the calculated FEA stiffness in both compression and tension. The increase of strut diameter per topology yielded random overall increase from FEA stiffness.

Since all stiffness responses were calculated from resulting effective modulus, each effective modulus was compared to the modulus of EOS MS1, 180GPa [14]. A plot of percent effective modulus to EOS MS1 verses unit cell density is shown in Figure 16.

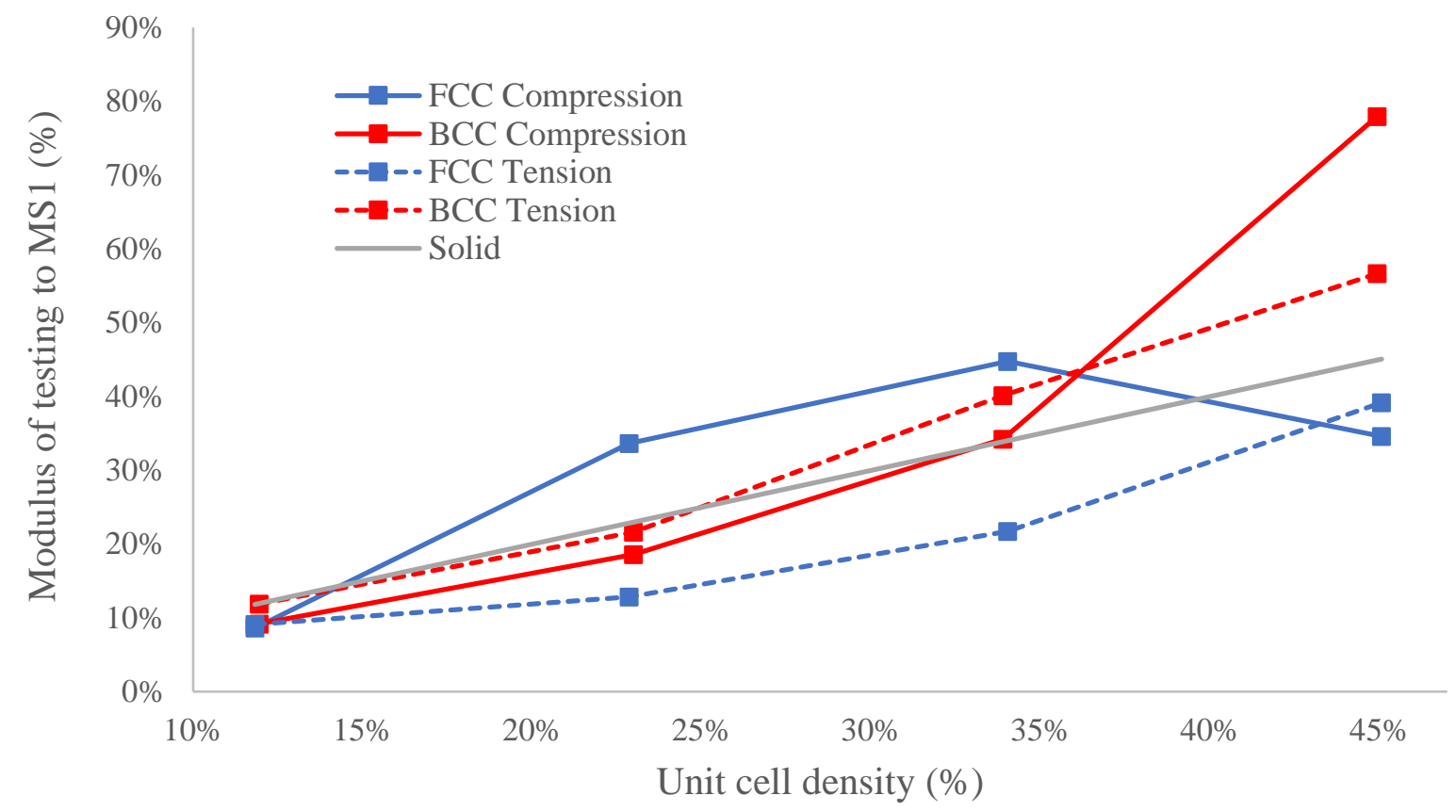

Figure 16. Effective percent modulus for non-filleted specimens to solid maraging steel per unit cell mass density. 
Figure 16 shows that for a specified unit cell topology and mass density, a projected percent effective modulus to solid maraging steel can be determined. As stated, only one specimen from each configuration was tested. For the largest unit cell density in both FCC and BCC specimen, the compressive effective modulus results appeared to be outliers since these results were drastically different from the trending data. This plot is useful to know for future fabrication of either FCC or BCC lattices because it shows which unit cell and density will have a greater effective modulus when compared to a partially dense unit cell of maraging steel with no lattice.

The final iteration of specimens incorporated fillets to all strut connections with the top and bottom face within the unit cell. This was to test whether the addition of mass at the cell connections would improve overall specimen stiffness in either tension or compression. As shown in Figures 11a and 11b, the modeled fillet radii were $0.5 \mathrm{~mm}, 1.0 \mathrm{~mm}$, and $1.42 \mathrm{~mm}$ or $1.5 \mathrm{~mm}$. Due to geometric constrains in SolidWorks, $1.42 \mathrm{~mm}$ radii fillets would be used in place of $1.5 \mathrm{~mm}$ radii fillets for some specimen.

Once the final iteration of specimens with fillets were built, each specimen was weighted, measured, and compared to modeled specimen. Table 11 and Table 12 show FCC and BCC weight comparisons respectively between modeled and printed. 


\begin{tabular}{|c|c|c|c|c|}
\hline $\begin{array}{c}\text { Modeled } \\
\text { strut } \\
\text { diameter } \\
(\mathrm{mm})\end{array}$ & $\begin{array}{c}\text { Fillet size } \\
(\mathrm{mm})\end{array}$ & $\begin{array}{c}\text { SolidWorks } \\
\text { weight } \\
\text { calculation }(\mathrm{g})\end{array}$ & $\begin{array}{c}\text { Measured } \\
\text { weight }(\mathrm{g})\end{array}$ & $\begin{array}{c}\text { Measured weight } \\
\text { to SolidWorks } \\
\text { preditction }(\%)\end{array}$ \\
\hline \multirow{3}{*}{0.855} & 0.5 & 17.59 & 18.0 & 102.5 \\
\cline { 2 - 5 } & 1.0 & 17.68 & 18.1 & 102.4 \\
\hline \multirow{3}{*}{1.215} & 1.42 & 17.83 & 18.2 & 102.1 \\
\cline { 2 - 5 } & 0.5 & 18.48 & 18.6 & 100.6 \\
\cline { 2 - 5 } & 1.0 & 18.60 & 18.7 & 100.3 \\
\hline \multirow{3}{*}{1.51} & 1.5 & 18.82 & 18.9 & 100.2 \\
\cline { 2 - 5 } & 1.0 & 19.38 & 19.2 & 99.1 \\
\cline { 2 - 5 } & 1.5 & 19.52 & 19.3 & 99.0 \\
\cline { 2 - 5 } & 0.5 & 20.27 & 19.6 & 98.9 \\
\cline { 2 - 5 } & 1.0 & 20.43 & 19.6 & 96.9 \\
\hline
\end{tabular}

Table 11. Weight comparisons for all FCC fillet specimens.

The two smallest strut diameter sizes in FCC specimens had an increase in weight across all

filleted specimens while the two largest strut sizes had a decrease in weight. The largest increase in weight came in the $0.855 \mathrm{~mm}$ strut $0.5 \mathrm{~mm}$ filleted specimen with an increase of $2.5 \%$. The largest decrease in weight was in all the $1.77 \mathrm{~mm}$ strut specimen with a decrease of $3.1 \%$.

\begin{tabular}{|c|c|c|c|c|}
\hline $\begin{array}{c}\text { Modeled } \\
\text { strut } \\
\text { diameter } \\
(\mathrm{mm})\end{array}$ & $\begin{array}{c}\text { Fillet size } \\
(\mathrm{mm})\end{array}$ & $\begin{array}{c}\text { SolidWorks } \\
\text { weight } \\
\text { calculation }(\mathrm{g})\end{array}$ & $\begin{array}{c}\text { Measured } \\
\text { weight }(\mathrm{g})\end{array}$ & $\begin{array}{c}\text { Measured weight } \\
\text { to SolidWorks } \\
\text { preditction }(\%)\end{array}$ \\
\hline \multirow{4}{*}{1.27} & 0.5 & 17.61 & 18.2 & 103.4 \\
\cline { 2 - 5 } & 1.0 & 17.74 & 18.3 & 103.4 \\
\cline { 2 - 5 } & 1.5 & 17.98 & 18.5 & 103.1 \\
\cline { 2 - 5 } & 0.5 & 18.50 & 19.2 & 103.7 \\
\cline { 2 - 5 } & 1.0 & 18.66 & 19.3 & 103.4 \\
\hline \multirow{3}{*}{2.30} & 1.5 & 18.96 & 19.6 & 103.2 \\
\cline { 2 - 5 } & 1.0 & 19.38 & 20.1 & 103.5 \\
\cline { 2 - 5 } & 1.5 & 19.57 & 20.1 & 102.9 \\
\hline \multirow{3}{*}{2.75} & 0.5 & 20.28 & 20.4 & 103.6 \\
\cline { 2 - 5 } & 1.0 & 20.48 & 21.1 & 103.0 \\
\cline { 2 - 5 } & 1.5 & 20.79 & 21.4 & 103.1 \\
\hline
\end{tabular}

Table 12. Weight comparisons for all BCC fillet specimens. 
All BCC filleted specimens yielded an increase in weight, consistently $2.9 \%$ to $3.7 \%$ heavier than SolidWorks calculations. The largest increase in weight was in the $1.83 \mathrm{~mm}$ strut $0.5 \mathrm{~mm}$ filleted specimen with $3.7 \%$ increase in weight.

Table 13 and Table 14 shows FCC and BCC strut diameter comparisons respectively between modeled and printed. Individual struts were measured by hand using digital calipers.

\begin{tabular}{|c|c|c|c|}
\hline $\begin{array}{c}\text { Modeled } \\
\text { strut } \\
\text { diameter } \\
(\mathrm{mm})\end{array}$ & $\begin{array}{c}\text { Fillet size } \\
(\mathrm{mm})\end{array}$ & $\begin{array}{c}\text { Measured } \\
\text { strut diameter } \\
(\mathrm{mm})\end{array}$ & $\begin{array}{c}\text { Measured to } \\
\text { modeled strut } \\
\text { diameter }(\%)\end{array}$ \\
\hline \multirow{3}{*}{0.855} & 0.5 & 0.88 & 102.9 \\
\cline { 2 - 4 } & 1.0 & 0.88 & 102.9 \\
\cline { 2 - 4 } & 1.42 & 0.88 & 102.9 \\
\hline \multirow{3}{*}{1.215} & 0.5 & 1.23 & 101.2 \\
\cline { 2 - 4 } & 1.0 & 1.25 & 102.9 \\
\cline { 2 - 4 } & 1.5 & 1.24 & 102.1 \\
\hline \multirow{3}{*}{1.51} & 0.5 & 1.53 & 101.3 \\
\cline { 2 - 4 } & 1.0 & 1.54 & 102.0 \\
\hline & 1.5 & 1.53 & 101.3 \\
\cline { 2 - 4 } & 0.5 & 1.80 & 101.7 \\
\cline { 2 - 4 } & 1.0 & 1.80 & 101.7 \\
\hline
\end{tabular}

Table 13. Comparison of modeled to measured filleted FCC specimens.

All FCC specimens were measured to have larger strut diameters than modeled. The closest measured specimen to modeled was in the $1.215 \mathrm{~mm} 0.5 \mathrm{~mm}$ fillet radius specimen with only a $1.2 \%$ increase in strut diameter. The largest measured difference was in the $1.215 \mathrm{~mm}$ strut $1.0 \mathrm{~mm}$ fillet radius specimen as well as in all $0.855 \mathrm{~mm}$ strut specimen with a $2.9 \%$ increase in strut diameter. 


\begin{tabular}{|c|c|c|c|}
\hline $\begin{array}{c}\text { Modeled } \\
\text { strut } \\
\text { diameter } \\
(\mathrm{mm})\end{array}$ & $\begin{array}{c}\text { Fillet size } \\
(\mathrm{mm})\end{array}$ & $\begin{array}{c}\text { Measured } \\
\text { strut diameter } \\
(\mathrm{mm})\end{array}$ & $\begin{array}{c}\text { Measured to } \\
\text { modeled strut } \\
\text { diameter }(\%)\end{array}$ \\
\hline \multirow{3}{*}{1.27} & 0.5 & 1.30 & 102.4 \\
\cline { 2 - 4 } & 1.0 & 1.31 & 102.8 \\
\cline { 2 - 4 } 1.83 & 1.5 & 1.30 & 102.4 \\
\cline { 2 - 4 } & 0.5 & 1.87 & 102.2 \\
\cline { 2 - 4 } & 1.0 & 1.87 & 102.2 \\
\hline \multirow{3}{*}{2.30} & 1.5 & 1.87 & 102.2 \\
\cline { 2 - 4 } & 0.5 & 2.32 & 100.9 \\
\cline { 2 - 4 } & 1.0 & 2.32 & 100.9 \\
\hline \multirow{3}{*}{2.75} & 1.5 & 2.32 & 100.9 \\
\cline { 2 - 4 } & 0.5 & 2.75 & 100.0 \\
\cline { 2 - 4 } & 1.0 & 2.76 & 100.4 \\
\hline
\end{tabular}

Table 14. Comparison of modeled to measured filleted BCC specimens.

All BCC specimens were measured to have larger strut diameters than modeled. The $2.75 \mathrm{~mm}$ strut $0.5 \mathrm{~mm}$ fillet radius specimen was measured to be exactly as modeled. The largest measured difference was in the $1.27 \mathrm{~mm}$ strut $1.0 \mathrm{~mm}$ fillet radius specimen with a $2.8 \%$ increase in strut diameter.

All filleted specimens were tested in the Instron 5569A in both compression and tension. The resulting stiffness' are shown in Table 15 for FCC specimens and Table 16 for BCC specimens. As like the second iteration, only 1 specimen was tested per topology, strut diameter, and fillet size configuration. 


\begin{tabular}{|c|c|c|c|}
\hline $\begin{array}{c}\text { Modeled } \\
\text { strut } \\
\text { diameter } \\
(\mathrm{mm})\end{array}$ & $\begin{array}{c}\text { Fillet size } \\
(\mathrm{mm})\end{array}$ & $\begin{array}{c}\text { Measured } \\
\text { tensile } \\
\text { stiffness } \\
(\mathrm{kN} / \mathrm{mm})\end{array}$ & $\begin{array}{c}\text { Measured } \\
\text { compressive } \\
\text { stiffness } \\
(\mathrm{kN} / \mathrm{mm})\end{array}$ \\
\hline \multirow{3}{*}{0.855} & 0.5 & 127.5 & 136.4 \\
\cline { 2 - 4 } & 1.0 & 160.9 & 93.7 \\
\cline { 2 - 4 } & 1.42 & 149.3 & 136.5 \\
\hline \multirow{3}{*}{1.215} & 0.5 & 228.6 & 640.3 \\
\cline { 2 - 4 } & 1.0 & 233.6 & 290.2 \\
\cline { 2 - 4 } & 1.5 & 272.1 & 336.8 \\
\cline { 2 - 4 } & 0.5 & 481.7 & 1113.3 \\
\hline \multirow{3}{*}{1.77} & 1.0 & 397.5 & 540.6 \\
\cline { 2 - 4 } & 1.5 & 569.8 & 516.3 \\
\cline { 2 - 4 } & 1.0 & 743.5 & 739.7 \\
\hline
\end{tabular}

Table 15. FCC filleted specimen compressive and tensile stiffness'.

Only two of the four FCC specimens, $1.215 \mathrm{~mm}$ and $1.77 \mathrm{~mm}$ strut diameters, had results of increasing tensile stiffness to increasing fillet radius. No FCC specimen in compression had a trend of increasing stiffness to increasing fillet radius.

\begin{tabular}{|c|c|c|c|}
\hline $\begin{array}{c}\text { Modeled } \\
\text { strut } \\
\text { diameter } \\
(\mathrm{mm})\end{array}$ & $\begin{array}{c}\text { Fillet size } \\
(\mathrm{mm})\end{array}$ & $\begin{array}{c}\text { Measured } \\
\text { tensile } \\
\text { stiffness } \\
(\mathrm{kN} / \mathrm{mm})\end{array}$ & $\begin{array}{c}\text { Measured } \\
\text { compressive } \\
\text { stiffness } \\
(\mathrm{kN} / \mathrm{mm})\end{array}$ \\
\hline \multirow{4}{*}{1.27} & 0.5 & 204.4 & 129.4 \\
\cline { 2 - 4 } & 1.0 & 248.7 & 286.8 \\
\cline { 2 - 4 } & 1.5 & 251.7 & 396.8 \\
\hline \multirow{3}{*}{2.83} & 0.5 & 365.5 & 227.8 \\
\cline { 2 - 4 } & 1.0 & 410.1 & 693.1 \\
\cline { 2 - 4 } & 1.5 & 475.0 & 462.4 \\
\cline { 2 - 4 } & 0.5 & 681.7 & 1206.5 \\
\hline \multirow{3}{*}{2.75} & 1.0 & 751.1 & 1582.9 \\
\cline { 2 - 4 } & 1.5 & 767.4 & 1208.2 \\
\cline { 2 - 4 } & 0.5 & 934.6 & 880.2 \\
\hline & 1.0 & 978.8 & 1827.0 \\
\hline
\end{tabular}

Table 16. BCC filleted specimen compressive and tensile stiffness'.

All BCC specimens resulted in increasing tensile stiffness to increasing fillet radius. No BCC specimens showed an increase in compressive stiffness to increasing fillet radius. 
Again, with all stiffness values calculated from effective modulus in filleted specimens, a comparison between percent effective tensile modulus to EOS MS1 modulus, 180GPa, with associated unit cell density for all specimen types was plotted in Figure 17.

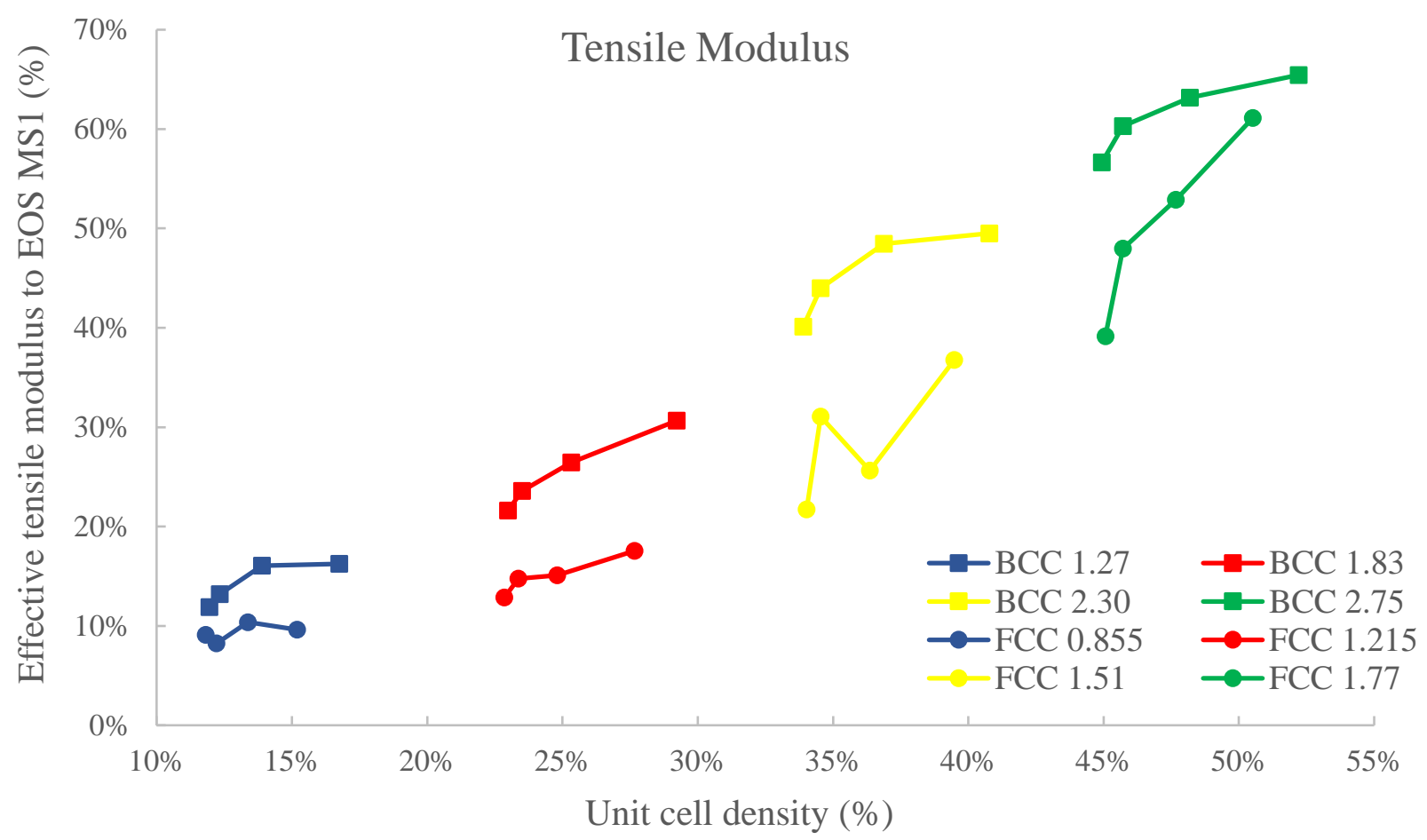

Figure 17. Effective percent tensile modulus per unit cell mass density of non-filleted and filleted specimens compared to solid maraging steel.

Figure 17 will be used in determining the effective percent modulus to EOS MS1 of any lattice specimen, FCC or BCC, filleted or non-filleted, in tensile loading corresponding to the desired unit cell mass density. All specimens have a positive trend in effective tensile modulus with increasing fillet size.

Some of the final iteration specimens were tested to failure. Specimens were only tested to failure in tension and without the use of an extensometer. Figure 18 shows an example of resulting failure test plot of true stress $(\mathrm{MPa})$ vs. true strain $(\mathrm{mm} / \mathrm{mm})$. 


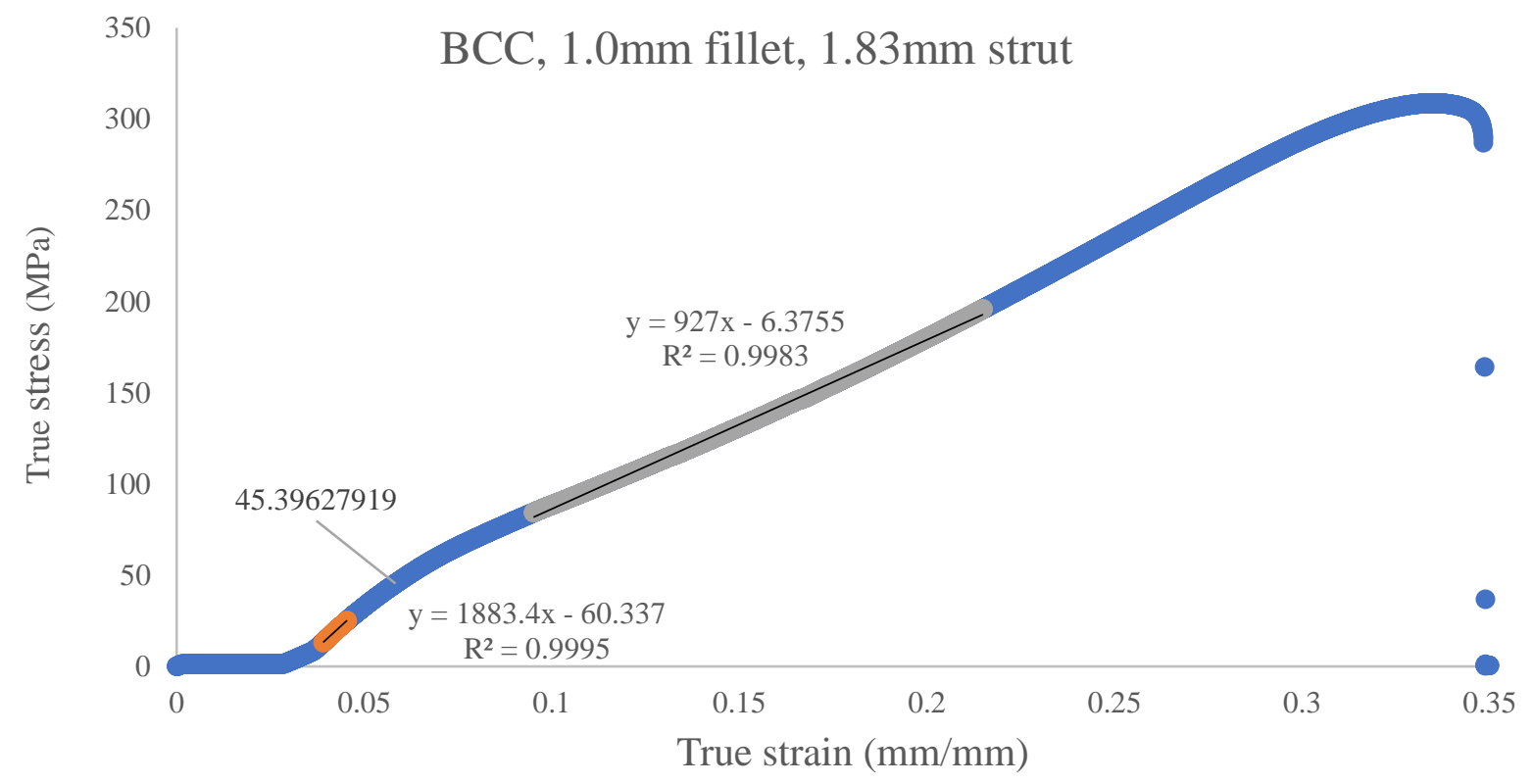

Figure 18. Plot of BCC $1.0 \mathrm{~mm}$ fillet $1.83 \mathrm{~mm}$ strut diameter specimen to failure in tension.

Both stiffness' per test, the transition stress between stiffness', and maximum stress per test were calculated to determine if there is a correlation between fillet size and transition stress or peak stress. The two-calculated stiffness' per failure test of select FCC and BCC specimens are show in Table 17 and Table 18 respectively. The transitional stress and maximum stress per failure test for select FCC and BCC specimens are shown in Table 19 and Table 20 respectively. 


\begin{tabular}{|c|c|c|c|c|c|}
\hline \multirow{2}{*}{$\begin{array}{l}\text { Unit } \\
\text { Cell }\end{array}$} & $\begin{array}{l}\text { Strut } \\
\text { Dia }\end{array}$ & $\begin{array}{c}\text { Unit cell } \\
\text { mass }\end{array}$ & Fillet size & $\begin{array}{c}\text { 1st } \\
\text { stiffness }\end{array}$ & $\begin{array}{c}\text { 2nd } \\
\text { stiffness }\end{array}$ \\
\hline & $(\mathrm{mm})$ & $(\%)$ & $(\mathrm{mm})$ & $(\mathrm{kN} / \mathrm{mm})$ & $(\mathrm{kN} / \mathrm{mm})$ \\
\hline \multirow{16}{*}{ FCC } & \multirow{4}{*}{0.855} & 11.8 & 0.0 & 13.2 & 7.5 \\
\hline & & 12.2 & 0.5 & 7.3 & 5.2 \\
\hline & & 13.4 & 1.0 & 16.5 & 3.9 \\
\hline & & 15.2 & 1.42 & 14.7 & 3.9 \\
\hline & \multirow{4}{*}{1.215} & 22.9 & 0.0 & 14.8 & 6.3 \\
\hline & & 23.4 & 0.5 & 15.8 & 6.3 \\
\hline & & 24.8 & 1.0 & 19.3 & 8.4 \\
\hline & & 27.7 & 1.5 & 14.8 & 7.7 \\
\hline & \multirow{4}{*}{1.51} & 34.0 & 0.0 & 13.5 & 8.7 \\
\hline & & 34.5 & 0.5 & 15.0 & 9.2 \\
\hline & & 36.4 & 1.0 & 15.8. & 9.2 \\
\hline & & 39.5 & 1.5 & 16.1 & 9.3 \\
\hline & \multirow{4}{*}{1.77} & 45.1 & 0.0 & 19.7 & 9.4 \\
\hline & & 45.7 & 0.5 & 16.6 & 8.3 \\
\hline & & 47.7 & 1.0 & 17.5 & 9.1 \\
\hline & & 50.5 & 1.42 & 21.4 & 7.7 \\
\hline
\end{tabular}

Table 17. Tensile stiffness' for failure testing of FCC specimens.

\begin{tabular}{|c|c|c|c|c|c|}
\hline \multirow{3}{*}{$\begin{array}{c}\text { Unit } \\
\text { Cell }\end{array}$} & $\begin{array}{c}\text { Strut } \\
\text { Dia }\end{array}$ & $\begin{array}{c}\text { Unit cell } \\
\text { mass }\end{array}$ & Fillet size & $\begin{array}{c}\text { 1st } \\
\text { stiffness }\end{array}$ & $\begin{array}{c}\text { 2nd } \\
\text { stiffness }\end{array}$ \\
\cline { 2 - 6 } & $(\mathrm{mm})$ & $(\%)$ & $(\mathrm{mm})$ & $(\mathrm{kN} / \mathrm{mm})$ & $(\mathrm{kN} / \mathrm{mm})$ \\
\hline \multirow{4}{*}{ BCC } & \multirow{3}{*}{1.27} & 11.9 & 0.0 & 12.4 & 6.6 \\
\cline { 3 - 6 } & & 12.3 & 0.5 & 13.5 & 5.9 \\
\cline { 3 - 6 } & & 13.9 & 1.0 & 15.0 & 6.4 \\
\cline { 3 - 6 } & \multirow{3}{*}{1.83} & 16.8 & 1.5 & 15.2 & 7.0 \\
\cline { 3 - 6 } & & 23.0 & 0.0 & 19.2 & 9.1 \\
\cline { 3 - 6 } & & 23.5 & 0.5 & 16.8 & 9.2 \\
\cline { 3 - 6 } & & 25.3 & 1.0 & 18.8 & 9.3 \\
\cline { 3 - 6 } & 2.75 & 44.9 & 1.5 & 19.4 & 9.4 \\
\hline
\end{tabular}

Table 18. Tensile stiffness' for failure testing of BCC specimens. 
Only 2 of the 4 strut diameters were tested in BCC specimen's. This is due to loading needed to fail specimens being excessive. The $2.75 \mathrm{~mm}$ strut diameter, non-filleted specimen was tested and did not fail. The face inside the gripping section failed instead. It was then decided to only test specimens with strut diameters lower than $2 \mathrm{~mm}$.

Failure results were significantly smaller than previously tested specimens. There is also no apparent trend in increasing strut or fillet size to increase in tensile stiffness for either the FCC or BCC specimens.

\begin{tabular}{|c|c|c|c|c|}
\hline \multirow[t]{2}{*}{$\begin{array}{l}\text { Unit } \\
\text { Cell }\end{array}$} & $\begin{array}{c}\text { Strut } \\
\text { Dia }\end{array}$ & $\begin{array}{l}\text { Fillet } \\
\text { size }\end{array}$ & $\begin{array}{c}\text { Stress at } \\
\text { stiffness } \\
\text { transition }\end{array}$ & $\begin{array}{c}\text { Max } \\
\text { Stress }\end{array}$ \\
\hline & $(\mathrm{mm})$ & $(\mathrm{mm})$ & $(\mathrm{N})$ & (Mpa) \\
\hline \multirow{16}{*}{ FCC } & \multirow{4}{*}{0.855} & 0.0 & 35 & 62 \\
\hline & & 0.5 & 28 & 56 \\
\hline & & 1.0 & 34 & 55 \\
\hline & & 1.42 & 41 & 54 \\
\hline & \multirow{4}{*}{1.215} & 0.0 & 42.5 & 145 \\
\hline & & 0.5 & 34.7 & 191 \\
\hline & & 1.0 & 49 & 182 \\
\hline & & 1.5 & 50.6 & 186 \\
\hline & \multirow{4}{*}{1.51} & 0.0 & 32 & 219 \\
\hline & & 0.5 & 33 & 270 \\
\hline & & 1.0 & 32 & 312 \\
\hline & & 1.5 & 31 & 315 \\
\hline & \multirow{4}{*}{1.77} & 0.0 & 46 & 244 \\
\hline & & 0.5 & 49 & 370 \\
\hline & & 1.0 & 52.5 & 575 \\
\hline & & 1.42 & 47.5 & 600 \\
\hline
\end{tabular}

Table 19. Transition stress and maximum stress during failure testing of FCC specimen. 


\begin{tabular}{|c|c|c|c|c|}
\hline \multirow{3}{*}{$\begin{array}{c}\text { Unit } \\
\text { Cell }\end{array}$} & $\begin{array}{c}\text { Strut } \\
\text { Dia }\end{array}$ & $\begin{array}{c}\text { Fillet } \\
\text { Size }\end{array}$ & $\begin{array}{c}\text { Stiffness } \\
\text { Transition } \\
\text { Load }\end{array}$ & $\begin{array}{c}\text { Max } \\
\text { Stress }\end{array}$ \\
\cline { 2 - 5 } & $(\mathrm{mm})$ & $(\mathrm{mm})$ & $(\mathrm{N})$ & $(\mathrm{Mpa})$ \\
\hline & & 0 & 22.5 & 127 \\
\cline { 3 - 5 } & \multirow{4}{*}{1.27} & 0.5 & 28 & 128 \\
\cline { 3 - 5 } & & 1 & 32 & 127 \\
\cline { 3 - 5 } & & 1.5 & 28 & 129 \\
\cline { 3 - 5 } & \multirow{3}{*}{1.83} & 0 & 43.5 & 263 \\
\cline { 3 - 5 } & & 0.5 & 49 & 296 \\
\cline { 3 - 5 } & & 1.5 & 45.5 & 309 \\
\cline { 3 - 5 } & 2.75 & 0 & 40 & 307 \\
\hline
\end{tabular}

Table 20. Transition stress and maximum stress during failure testing of BCC specimen.

While not every FCC and BCC specimen tested to failure yielded increasing maximum stress to increasing fillet size, as the strut diameter increases, the maximum stress increases for both FCC and $\mathrm{BCC}$ specimens. There is no trend between transition stress to either increasing fillet size or increasing strut diameter.

Figure 19 shows the fracturing of specimens after failure testing.

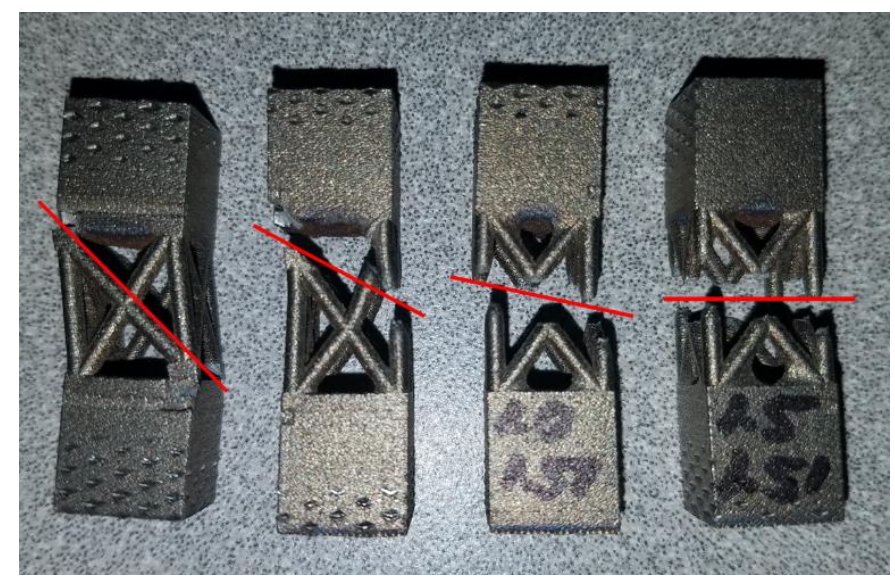

Figure 19. Failure of non-fillet and fillet specimens. Left to right: No fillet, $0.5 \mathrm{~mm}$ fillet, $1.0 \mathrm{~mm}$ fillet, $1.5 \mathrm{~mm}$ fillet

Most all non-fillet specimens failed in shear, breaking at the connections of struts to the additional masses. As fillets were introduced to the unit cell, failure transitioned to a perpendicular fracture to the direction the load was being applied. As the fillet size within the 
unit cell increased, the unit cells began to fracture in the middle of the lattice rather than at the connections between struts and additional masses used for gripping. 


\section{CONCLUSIONS}

By increasing the strut diameter size within the lattice unit cell, the stiffness and effective modulus increases. Body-centered lattices' yield a higher stiffness and higher effective modulus than face-centered lattices' in all iterations used in this study. In the first iteration, even though comparison to finite element analysis (FEA) stiffness results were poor, as strut diameter increased so did the stiffness of the unit cell topology. A reason for poor comparison to FEA was due to the compression fixtures having a softer material than the specimens being tested, no use of an extensometer, and fracturing of the $0.5 \mathrm{~mm}$ plates on the top and bottom of the lattice structures. In the second iteration of body-centered and face-centered topologies, testing stiffness and effective modulus increased again as the strut diameter of the unit cell increased. Also, testing results yielded greater stiffness than predicted from the linear, static FEA performed in SolidWorks. A key to this was the incorporation of $10 \mathrm{~mm}$ of solid mass on either side of the lattice structures to allow the mechanical tester to hold the specimen during testing. Also, with the use of an extensometer, a more accurate representation of displacement in the lattice structure was displayed. In the last iteration of specimens, with the addition of mass via fillets at the strut connections to the top and bottom gripping sections, an increasing trend in stiffness and effective modulus occurs. While all specimens do not have increasing percent modulus to increasing fillet radius, all specimens have a positive trend in effective tensile modulus with increasing fillet radius. There was no trend of increasing stiffness and effective modulus to fillet radius when specimens were tested in compression.

While tensile failure tests yielded poor stiffness results, the inspection of the fractures post testing indicate that the addition of fillets decrease and effectively remove most stress concentration at the connections with the struts and additional mass gripping sections. Loading 
was carried more uniformly in the entire unit cell rather than being highly concentrated at the connection locations. 


\section{RECOMMENDATIONS}

Direct metal laser sintering has proven to be an excellent source for fabricating lattice structures for production purposes. While this study investigated and characterized a single unit cell of body-centered and face-centered cells, lattice structures are more commonly found in "networks" of unit cells. In future work, this report recommends the fabrication of multiple unit

cell specimen: using similar mass volume reduction cells, but fabricate in a system of lattice cells to test the behavior of multiple unit cells in connection.

This report also only looked at lattice structure mechanical properties with no post-build heat-treatment or post-build stress relieving. As reported in BACKGROUND, studies involving maraging steel that used post-build heat-treatment found significant increases in strength but significant decrease in elongation. Conditional on the applications needed for lattice structures, heat treatment could prove useful and would need further investigation from this report. Also stress relieving lattice structures could be investigated. While lattice structures do not have large cross-sections, the DMLS process could cause lattice structures to withhold some residual internal stress due to high laser wattage with high scan speeds, which could influence performance of the lattice structure as a whole.

It is recommended to explore testing lattice specimens in different mechanical apparatuses and in other methods besides tension and compression. This study used only wedge type gripping during testing. Possibly using hydraulic or vice grips could improve testing results. The study also did not investigate fatigue, flexural, or torsional properties for lattice structures due to both time constraints and samples that were fabricated not lending themselves to this. These tests would prove noteworthy and possibly vital to completely characterize lattice structures. 
While this study used a simple linear, static FEA in SolidWorks, it is recommended to explore other types of finite element analysis software's. Different software FEA results comparison to the FEA performed in SolidWorks from this study could improve the full characterization of these structures further.

Lastly, an investigation into the extensometer could be done. With all results from the testing conducted with an extensometer being much greater than $100 \%$ when compared to FEA results, some greater than $300 \%$, it would be worth exploring the output data of the extensometer. To fully understand what the extensometer is reading, displaying and in what form would prove vital in future work. 


\section{REFERENCES}

1. Julia Pyper, "To Boost Gas Mileage, Automakers Explore Lighter Cars," Scientific American, 27 Sept. 2012, https://www.scientificamerican.com.

2. Sebastian Blanco, "How Does Weight Affect a Vehicle's Efficiency?" Autoblog, 29 Nov. 2016, http://www.autoblog.com.

3. Peggy Malnati, "Automotive Composites: Mass Reduction for Mass Production," Plastics Engineering, Sept. 2016. http://read.nxtbook.com/wiley/plasticsengineering.

4. Cassandra Patterson, "Crystal Lattice," Chemistry LibreTexts, 21 July 2016, https://chem.libretexts.org.

5. Chunze Yan, Liang Hao, Ahmed Hussein, Simon Lawrence Bubb, Philippe Young, and David Raymont, "Evaluation of Light-weight AlSi10Mg Periodic Cellular Lattice Structures Fabricated via Direct Metal Laser Sintering," ScienceDirect, Apr. 2014, http://www.sciencedirect.com.

6. Chunze Yan, Liang Hao, Ahmed Hussein, Philippe Young, Juntong Huang, and Wei Zhu. Microstructure and Mechanical Properties of Aluminium Alloy Cellular Lattice Structures Manufactured by Direct Metal Laser Sintering. Materials Science and Engineering 628:238-246.

7. Nicola Contuzzi, Sabina L. Campanelli, Caterina Casavola, and Luciano Lamberti. "Manufacturing and Characterization of 18Ni Marage 300 Lattice Components by Selective Laser Melting." Materials, August 2013, www.mdpi.com/journal/materials.

8. Hamza Alsalla, Liang Hao, and Christopher Smith. 2016. Fracture toughness and tensile strength of 316L stainless steel cellular lattice structures manufactured using the selective laser melting technique. Materials Science and Engineering 669:1-6.

9. Mohammad Jeelani, "Microlattice: A Lightest Metal Ever Invented in Aerospace Engineering," Boeing, 19 Nov. 2015, https://aerospaceengineering.aero.

10. Qixiang Feng, Qian Tang, Zongmin Liu, Ying Liu, and Rossi Stechi, "An Investigation of the Mechanical Properties of Metallic Lattice Structures Fabricated Using Selective Laser Melting," SAGE Journals, Institution of Mechanical Engineers, 11 Oct. 2016, http://journals.sagepub.com.

11. Rasoul Mahshid, Hans Norgaard Hansen, and Klaus Loft Hojbjerre. 2016. Strength analysis and modeling of cellular lattice structures manufactured using selective laser melting for tooling applications. Materials and Deisgn 104:276-83. 
12. Chunze Yan, Liang Hao, Ahmed Hussein, and David Raymont. 2012. Evaluations of Cellular Lattice Structures Manufactured Using Selective Laser Melting. International Journal of Machine Tools and Manufacture 62:32-38.

13. Hendrickson, Joel W., "Use of Direct Metal Laser Sintering for Tooling in High Volume Production" (2015). All Graduate Plan B and other Reports. Paper 724.

14. Robert Stirling. 1993. Material Safety Data Sheet for Maraging Steel, MSl. Fairfax, VA: Defense Mapping Agency, Safety \& Health Division, Human Resources Directorate, Electro Optical Systems.

15. K. Kempen, E. Yasa, L. Thijs, J. P. Kruth, and J. Van Humbeeck. 2011. Microstructure and Mechanical Properties of Selective Laser Melted 18Ni-300 Steel. Physics Procedia 12.Part A:255-63.

16. M. Rombouts, E. Yasa, J. Luyten, J. Deckers, and J. Kruth. "Experimental Investigation of Charpy Impact Tests on Metallic SLM Parts." Catholic University of Leuven, Belgium, 2009, https://lirias.kuleuven.be.

17. Chaolin Tan, Kesong Zhu, Xin Tong, Yushan Huang, Jing Li, Wenyou Ma, Fuhai Li, and Tongchun Kuang. 2016. Microstructure and Mechanical Properties of 18Ni-300 Maraging Steel Fabricated by Selective Laser Melting. Proceedings of the 2016 6th International Conference on Advanced Design and Manufacturing Engineering (ICADME 2016).

18. J. P. Kruth, M. Badrossamay, E. Yasa, J. Deckers, L. Thijs, and J. Van Humbeeck. "Part and Material Properties in Selective Laser Melting of Metals." Catholic University of Leuven, Belgium. https://lirias.kuleuven.be.

19. "EOS Maraging Steel MS1," Think3D, 25 Mar. 2017, http://www.think3d.in.

20. "Stress Concentration," California State Polytechnic University, https://teamuv.org.

21. Ashwini Joshi, Vijay Kumar Karma. 2011. Effect on Strength of Involute Spur Gear by Changing the Fillet Radius Using FEA. International Journal Of Scientific \& Engineering Research 2.9: n. pag.

22. Stefanie M. Hirt. Experimental Study of Fillets to Reduce Corner Effects in an Oblique Shock-Wave/Boundary-Layer Interaction. NASA Glenn Research Center.

23. Thomas J. Dolan, “A Photoelastic Study Of Stresses In Gear Tooth Fillets," Tech. Champaign, IL: University of Illinois, 1942, https://www.ideals.illinois.edu.

24. Herbert F. Hardrath, and Lachlan Ohman. A Study Of Elastic And Plastic Stress Concentration Factors Due To Notches And Fillets In Flat Plates. NASA National Advisory Committee for Aeronautics. 
25. Ian. Wright, "The Battle of Manufacturing: Additive vs Subtractive," ENGINEERING, 31 Aug. 2016, http://www.engineering.com.

26. "Additive Manufacturing vs Subtractive Manufacturing," Creative Mechanisms, 2016, https://www.creativemechanisms.com.

27. Howard J. Brown, “Additive Verses Subtractive Manufacturing,” DMass, 17 Jan. 2012, http://www.dmass.net.

28. Michael Armbruster, "3D Printing: Understanding Support Material," Product Design and Development, 14 Sept. 2015, http://www.pddnet.com.

29. "How Does DMLS - Direct Metal Laser Sintering Work?," GPI Prototype and Manufacturing Services, http://gpiprototype.com.

30. EOSINT M Technology. 2007. EOSINT MTechnology for Direct Metal Laser-Sintering (DMLS). 1-53. http://www.3dimpuls.com.

31. "Design Guidelines: Direct Metal Laser Sintering (DMLS)." Stratasys. https://www.stratasysdirect.com.

32. "Amerimold Workshop: Direct Metal Laser Sintering." Additive Manufacturing. 27 Dec. 2009. http://www.additivemanufacturing.media.

33. "Direct Metal Laser Sintering." Proto Labs. https://www.protolabs.com. 


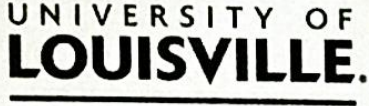

J.B. SPEED SCHOOL

OF ENGINEERING

MEMO TO: Academic Affairs Office

J. B. Speed School of Engineering

FROM:

\section{APPENDIX II}

APPOINTMENT OF MEMBERS

OF THE EXAMINATION COMMITTEE $\frac{-5 / 30 / 17}{\text { (Date) }}$

DR. TOM BERFIELD, MECHANICAL

SUBJECT: Appointment of Members of the Master of Engineering Examination Committee for

ZACHARY DENZIK
(Student Name)
DR KEVIN MURPIY
Department Chair

\section{CONSTITUENCY OF EXAMINATION COMMITTEE}

It is recommended that the following individuals be officially designated as members of the Master of Engineering Examination Committee of subject MEng candidate. Each of these persons has been contacted and has agreed to serve on the Examination Committee.
1. DR. TOM BERFIELD
2. DR. TOM STARR
Thesis Director
3. DR. $\angle I$ YANG Member
4. Member Member

In addition to the foregoing membership of the Examination Committee, it is requested that the following committee representatives from outside Speed School, each of whom has agreed to serve, be appointed as Members of the Examination Committee:

1. External Member Name TIM GORNET

\section{(Mailing Address and email address of external member)}

\section{External Member Name}

(Mailing Address and email address of external member) 


\section{APPENDIX II \\ (Continued)}

II. M.ENG. PROJECT DESCRIPTION

A brief description of the proposed MEng project is as follows:

THROUGH THE USE OF DIRECT METAL LASER SINTERING,
THE INUESTIGATION OE LATTICE STRUCTURES VIA STIFFNCSS
RESPONSE WAS STUDIED. ALSO, WITH THE ADDITION OF

FILLETS TO THE CONNECTIONS OF LATTICE UNIT CELLS, THE
ANALYSIS OF THE UNIT CELL RESPONSE BETWEEN NON-FILLETED

Tentative title of the proposed MEng thesis (10 words or less): ILLETCD SPECIMENS AND WHAT

Tentative title of the proposed MEng thesis (10 words or less): IS THE RELATING TREND.

INVESTIGATION OF LATTICE STRUCTURES AND ANALYSIS

OF STRUT GEOMETRY

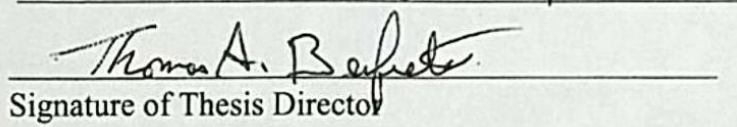

\section{APPROVAL BY DEPARTMENT CHAIR}

The Thesis Director has conferred with me relative to the investigation, thesis topic and committee membership of the indicated student, and I agree with the recommendations

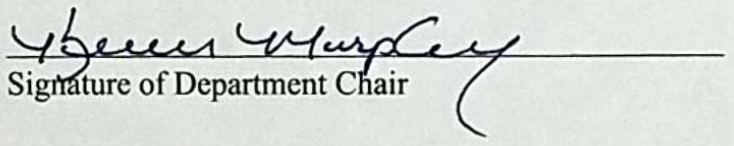

General Instructions:

The student in collaboration with the Thesis Director should prepare this form: original to the Department Chair, copy retained by the student, copy for Thesis Director's file, copy to each committee member and a copy to Academic Affairs Office.

Full-time students must submit the project description and constituency on the Master of Engineering examination committee according to the specific dates in Appendix I (MEng thesis timeline).

Part-time students must submit the project description and constituency on the Master of Engineering examination committee no later than one calendar year prior to the student's expected date of graduation. 


\section{APPENDIX III}

ORAL EXAMINATION REQUEST

UNIVERSITY OF LOUISVILLE

J. B. SPEED SCHOOL OF ENGINEERING

MEMO TO: Academic Affairs Office

$$
\frac{6 / 20 / 17}{(\text { Date })}
$$

FROM: DR. TOM BERFIELD (MEng Thesis Director)

SUBJECT: MEng Oral Examination and Thesis Defense for ZACK DENZIK (Name of Student)

1. The oral examination and thesis defense of subject degree candidate will be held on of Week), $6 / 26 / 17$ (Building).

(Date), at 2:00 pm (Time) in Room No. 311 of

2. The title of the MEng Thesis is:

INVESTIGATION OF LATILE STRUCTURES AND

ANALYSIS OF STRUT GEOMEIRY

(Signature of Thesis Director)

THE STUDENT IS RESPONSIBLE FOR DISTRIBUTION OF THESE COPIES

1) Department Chair DR. KEVIN MURPHY

2) Thesis Director DR. TOM BERFIELD

3) Committee Member DR. TOM STARR.

4) Committee Member DR. LI YANG

5) Committee Member TIM GORNET

6) Committee Member 


\section{APPENDIX IV}

\section{ORAL EXAMINATION RESULTS}

UNIVERSITY OF LOUISVILLE

J. B. SPEED SCHOOL OF ENGINEERING

MEMORANDUM TO: Academic Affairs Office

$\frac{6 / 20 / 17}{\text { (Date) }}$

FROM: DR. TOM BERFIELD (Thesis Director)

SUBJECT: MEng Oral Examination and Thesis Defense For ZACK DENZIK

(Name of Student)

1. The oral examination and thesis defense of the above named degree candidate was held on

MONDAY (Day of Week),
311 in VOGT (Building).

2. The examination and defense began at 2:00 pim (Time) and was concluded at 4:00 pm (Time).

3. The candidate PASSED AILED (delete whichever not applicable) the oral examination and thesis defense.

4. Qualifications or clarifying statements considered to be important by the Thesis Director (Optional):

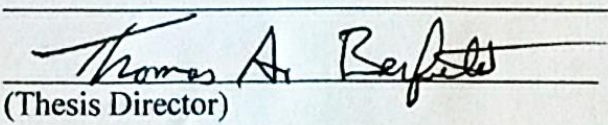

Copy to: Department Chair 


\section{APPENDIX IX}

\section{Nonexclusive License for Electronic Thesis and Dissertations}

University Libraries at University of Louisville ("UL") and Author wish to enter into a licensing arrangement in order to preserve the thesis or dissertation Work of Author ("the Work") identified and described more fully herein,

INVESTGGATON OF LATILE STRUCTORES AND ANALYSLS
OF STRUT GEOMETRY

and to make the Work accessible and widely available for dissemination through and using a range of extant and later developed technologies and formats consistent with the goals of scholarship and library practices in the scholarly community.

To that end:

1. Author grants to UL, its agents, assigns, and necessary contractors or third parties, nonexclusive, irrevocable, and worldwide rights and license to reproduce, distribute, prepare collectives, compilation, and derivatives, perform, display, and otherwise alter and modify the Work consistent with this license and the needs and requirements of relevant technologies used to effect the intent of this license as determined by UL at its sole discretion. Author also waives any "moral rights" that may exist in elements of the Work. Author otherwise retains all other rights in the Work and bears sole responsibility for complying with copyright and other legal requirements in the U.S. and elsewhere as they may govern the ownership and enforcement rights of Author.

2. Author makes the following representations and warranties regarding the Work:

a. The Work is the sole and original work of Author.

b. Author has full authority, capacity, and power to enter into this license.

c. The Work contains no audio, information, prograrmming. textual material, video, or other content or component that (1) is defamatory. (2) breaches of ocherwise violates any existing agreements between Author and another party including confidentiality agreements and like arrangements, (3) infringes any intellectual property rights, including copyright, patent, trademark, trade secret or other rights of a third party, (4) and that any incluston of copyrighted material into the Work was made with written permission or is consistent with a "rexionable and good faith" application of fair use as applied and codified in 17 U.S.C. \$107 of Unitad States law.

3. Author agrees to hold UL harmless and to indemnify UL for reasonable attorney fees, costs, and damages in the event of a claim or allegation arising from violations of clause 2 or arising from the breach of any representations and warranties expressed in this licensc.

4. Author acknowledges that UL may remove or otherwise disable the Work under the foree of law, for allegations of infringement or other unlawful occurrences, or due to circumstances beyond UL control and that UL makes no representations or warranties whatsocver about the ETD program or whether the Work will be included in it or any iterations and versions of it today or in the future.

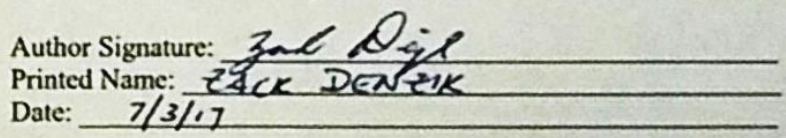


Investigation of lattice structures

and

Analysis of strut geometry

Submitted by: Joky K. \&

A Thesis Approved on

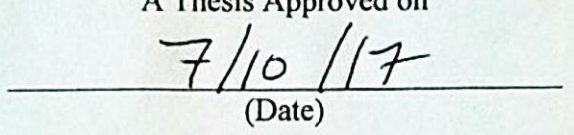

by the Following Reading and Examination Committee:
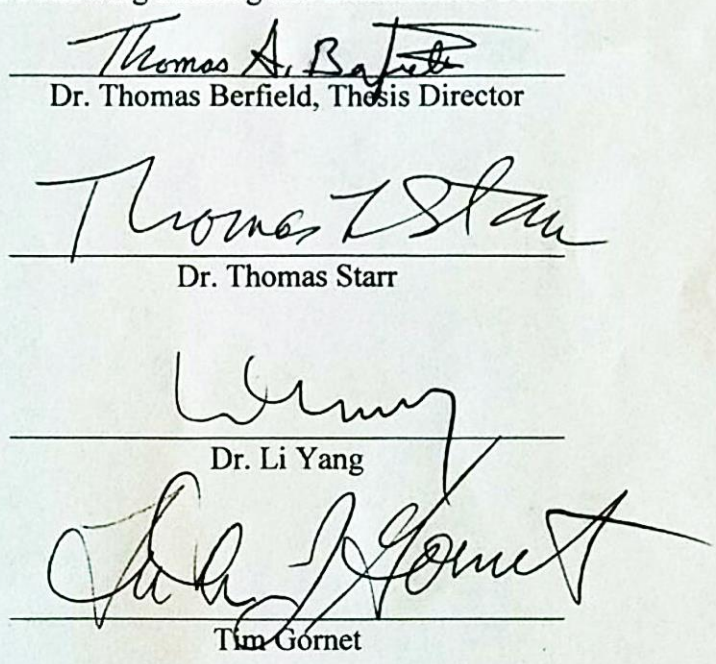

ii

56 